\title{
Variability of the low-level circulation of the South American Monsoon analysed with complex networks
}

\author{
Maximilian Gelbrecht ${ }^{1,2,3, a}$, Niklas Boers ${ }^{1,3,4}$, and Jürgen Kurths ${ }^{1,2,5}$ \\ 1 Potsdam Institute for Climate Impact Research, Potsdam, Germany \\ 2 Department of Physics, Humboldt-Universität zu Berlin, Berlin, Germany \\ 3 Department of Mathematics and Computer Science, Freie Universität Berlin, Berlin, Germany \\ 4 Department of Mathematics and Global Systems Institute, University of Exeter, Exeter, UK \\ ${ }^{5}$ Lobachevsky State University of Nizhny Novgorod, Nizhnii Novgorod, Russia
}

Received 11 November 2020 / Accepted 26 May 2021 / Published online 21 June 2021 (C) The Author(s) 2021

\begin{abstract}
Understanding the variability of low-level atmospheric circulation regimes is key for understanding the dynamics of monsoon systems. The South American Monsoon is characterized by strong year-long trade winds that are channeled southward into the South American Low-Level Jet after crossing the Amazon basin, which in turn is elementary for the moisture transport to Southern South America. In this study, we utilize streamflow wind networks, a type of climate networks that tracks the local flow of the wind field, together with the analysis of composites of wind, precipitation, and geopotential height fields, to investigate the variability of the South American low-level circulation. The streamflow wind networks are used here as they are able to directly track the wind flow and encode its spatiotemporal characteristics in their topology. We focus on intraseasonal variations in terms of active and break monsoon phases on the one hand, and on the interannual variability in terms of the impacts of the El Niño-Southern Oscillation on the other hand. Our findings highlight the importance of the South American Low-Level Jet, its spatial position and variability. Our study reveals the relation of the active and break regimes to anomalous highand low-pressure systems over the southern Atlantic that are connected to Rossby wave trains from the southern Pacific, as well as the impact of these regimes on the cross-equatorial low-level flow. In addition, the streamflow networks that we use demonstrate significant shifts of the dominant wind flow pattern during El Niño and La Niña episodes.
\end{abstract}

\section{Introduction}

Monsoon systems are the result of a complex interplay of atmospheric processes on various spatial and temporal scales [1]. The strength or activity of a monsoon is most easily noticeable in terms of anomalously high precipitation. The strength of the precipitation is naturally coupled to the low-level circulation of the monsoon system, so that different criteria for active and break monsoon phases based on precipitation, pressure systems and wind have been suggested $[2,3]$. The active and break phases are strongly connected to changes in the low-level circulation [1]. In the latter study, the authors formulated a criterion for the Asian-Australian Monsoon to distinguish between active and break phases solely based on the wind velocity at $850 \mathrm{hPa}$ and the outgoing longwave radiation (OLR, merely a proxy for precipitation) in certain reference regions. This concept was applied to the South American Monsoon System (SAMS) as well [4]. The SAMS is different from the classical monsoon systems such as the Indian Summer

\footnotetext{
${ }^{a}$ e-mail: gelbrecht@pik-potsdam.de (corresponding author)
}

Monsoon, because it does not exhibit the typical seasonal reversal of the low-level circulation [5]. Still, the SAMS features distinct dry and wet phases [6], and the reversal in the circulation system is actually present in the anomalies of the low-level winds [5]. The direction of this anomaly wind vector field can also be linked to the active and break phases of the SAMS during its wet season [4]. Predominately westerly wind anomalies at $850 \mathrm{hPa}$ in western Brazil and northern Bolivia are associated with active phases of the monsoon, whereas predominantly easterly wind anomalies in that region are associated with break phases [4]. The subdivision into active and break phase is solely based on the lowlevel wind direction in a small reference region, yet both phases exhibit large-scale differences [4]. This is especially true for the moisture transport from the tropical Amazon to subtropical southeastern South America (SESA), which is crucial for sufficient precipitation in this densely populated region [4]. One of the key features of the low-level circulation of the SAMS that we intend to study here is the South American Low-Level jet (SALLJ) $[6,7]$. The SALLJ is a wind system within the lowest $1-2 \mathrm{~km}$ at the eastern slopes of the Central Andes [8]. The SALLJ is essential for the low-level mois- 
ture flux from the tropical Amazon to SESA [8-11]. It is a crucial focus point of our investigation of spatiotemporal variations of the low-level circulation associated with active and break phases of the SAMS. In a previous study, the intraseasonal variability of the SALLJ and correspodingly, rainfall anomalies in SESA, have been shown to be dominated by Rossby Wave activity in the southern Pacific ocean [12]. The impact of the El Niño Southern Oscillation (ENSO) on the atmospheric circulation is another point of interest for our long-term climatological analysis, to corrobate studies auch as $[13,14]$ that investigate the impact of the ENSO on the SALLJ.

Complex networks have proven to be a valuable tool to investigate intricate spatiotemporal coupling structures in the climate system $[15,16]$. Networks are able to uncover and, upon a suitable quantification of the network topology, visualize these coupling structures remarkably well. Due to the large-scale seasonal changes in precipitation, wind and other observables, complex networks are especially well suited for the analysis of spatiotemporal couplings in monsoon systems [17-20] and also to infer jet-like behaviour [21].

Additionally, complex networks have also proven to be an effective tool for the analysis of larger-scale, interannual variability due to phenomena like the El Niño Southern Oscillation $[22,23]$. By employing climate networks it is also possible to distinguish different types of El Niño events [24]. Recent advances even suggest that networks can serve as early warning precursors of ENSO events or even predict ENSO events [25-27].

Climate networks are also a powerful tool to uncover teleconnections [28-30]. The climate network approach is not limited to scalar observables either, as networks from flows gained considerable attention, lately $[31,32]$.

To study the spatiotemporal characteristics distinguishing the active and break monsoon phases, we derive a statistical representation of the low-level wind field in terms of a complex network. The recently introduced streamflow wind networks are an especially suitable method for this task, because they directly track the wind flow and store its spatiotemporal characteristics in their topology [33]. Path-based network measures like the betweenness centrality exhibit large values along important features of the wind field like the SALLJ. This has recently been shown for the SAMS by comparing streamflow wind networks computed for the wet and dry season, respectively [33]. Here, we want to confirm that the developed methdodology yields reasonable results that are in accordance with - and corroborate the findings of previous studies of - a wellunderstood monsoon system like the SAMS. In this sense this study can be seen as a proof-of-concept of studying the variability of a climate subsystem with streamflow wind networks. By doing so and by exploring the spatiotemporal characteristics with it, we also hope to expand the knowledge of the active and break phases of the SAMS in terms of associated changes in the large-scale coupling structure.

In the following, we will first introduce the climatic setting of our study: the South American Monsoon
System and its active and break phases. Thereafter, we will introduce the employed methodology, namely, complex networks and specifically streamflow wind networks. These networks will be applied to the active and break phases first and, thereafter, to the different ENSO phases as well. The climatological implications of the results derived from our analysis of these different climatic conditions will finally be discussed in detail.

\subsection{Climatic setting of the South American Monsoon System}

The differential heating between the tropical Atlantic Ocean and the South American continent, together with the trade winds that are strong year-round, are key ingredients of the South American Monsoon System (SAMS) [6]. The trade winds are responsible for the low-level moisture transport from the tropical Atlantic ocean to the continent. The trade winds are, after crossing the Amazon basin, deflected by the Andes and channeled southward into the South American Low-Level Jet (SALLJ) (see Fig. 1). The SALLJ is a synoptic-scale wind system with highest speeds typically attained in Bolivia near Santa Cruz de la Sierra $[8,13,34,35]$. There exist different definitions of Low-Level Jets (LLJs) in general and of the SALLJ in particular. [36] defines LLJs as events which have to fulfill a certain velocity criterion: the Bonner criterion 1 demands a velocity of $15 \mathrm{~ms}^{-1}$ and a velocity decrease of at least 6 $\mathrm{ms}^{-1}$ at $3 \mathrm{~km}$ altitude. This is well above the mean velocities observed in the regions associated with the SALLJ. Typically, Bonner 1 events occur between 5 and 50 times per year depending on the exact observation point and year [10]. In contrast to this event-type definition, [7], e.g., regard LLJs as essential and permanent features of every subtropical monsoon system. In this study, we follow the line of [7] and speak of an enhanced SALLJ when there are positive velocity anomalies with a poleward direction at the eastern slopes of the Andes and of an suppressed SALLJ when there are negative velocity anomalies.

The SALLJ transports moisture from tropical South America (including the Amazon) to SESA (Fig. 1) [37, e.g]. The intensity and position of the SALLJ is connected to the occurrence of floods and droughts in SESA, as well as to the frequency, intensity, and size of Mesoscale Convective Systems (MCS) forming in SESA $[8,34]$. In this study, we will, therefore, put significant emphasis on the variability of the SALLJ. Depending on prevailing atmospheric conditions, the SALLJ exhibits two different regimes: it either has a pronounced southward component exiting in the Gran Chaco area (the so-called Chaco Jet), or a more pronounced eastward component exiting in southern Brazil (the No-Chaco Jet) $[11,38]$.

The largest precipitation differences between dry and wet seasons can be found in the southern Amazon (at about $10^{\circ} \mathrm{S}$ ), where precipitation peaks during austral summer (DJF) [6]. The SAMS was not recognized as a monsoon system for a long time until [5] showed that 


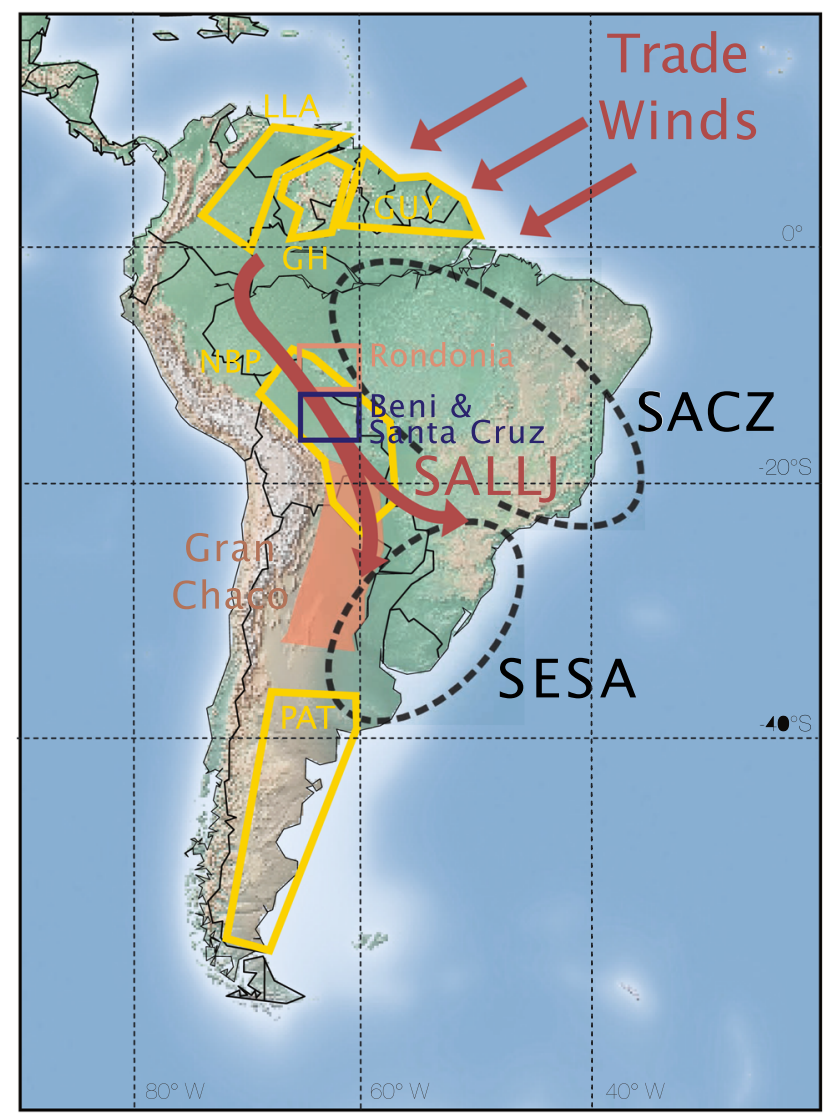

Fig. 1 Overview of important features of the low-level atmospheric circulation of the South American Monsoon System (SAMS). The trade winds and the South American Low-Level Jet (SALLJ) are marked in red. The South Atlantic Convergence Zone (SACZ), the main area of convection of the SAMS, and southeastern South America (SESA) are marked in black. In this study, active and break phases of the SAMS are distinguished based on the wind direction in the Bolivian districts Beni and Santa Cruz (BSC, marked in dark blue). The original study on active and break SAMS phases used a reference region slightly to the north, in the Brazilian province of Rondônia (marked in orange, see text) [4]. Various regions in South America that are referenced in this study are marked in yellow. These include (from north to south) the Llanos Plain (LLA), the Guyana Highlands (GH), the Guyanas without the Guyana Highlands (GUY), the eastern slopes of the Andes in northern Bolivia and western Paraguay (NBP) and Patagonia (PAT)

the climate of South America actually fulfills a slightly loosened criteria of a monsoon system: The key difference between the SAMS and other monsoon systems is that there is no seasonal reversal in the prevailing wind direction. However, [5] showed that this reversal does happen when looking at the anomaly wind vector field, instead. Such anomaly vectors are computed by removing the mean value componentwise. The reversal in the anomaly wind directions around the equator can be understood as an effect of the stronger atmospheric heating over the South American continent as com- pared to the tropical Atlantic ocean, which enhances the low-level winds from the Atlantic ocean toward the South American continent, superimposed on the yearround easterly direction of the trade winds.

Similarly to other monsoon systems, the SAMS exhibits active and break phases as well: [4] showed that the direction of the anomaly wind vectors in the Brazilian state Rondônia is an indicator for this activity. Based on previous observations, [4] picked a region in Rondônia $\left(9^{\circ}-13^{\circ} \mathrm{S}, 60^{\circ}-64^{\circ} \mathrm{W}\right)$ as a reference for classifying the wind. Rondônia is situated south of the Amazon basin and north of Bolivia. It is, therefore, heavily affected by the strength of the monsoon. Whereas the absolute wind field in Rondônia is northerly throughout the austral summer season (DJF), the direction of the anomaly wind field exhibits two distinct regimes: a westerly and an easterly regime. These regimes can be identified with active and break phases of the SAMS, as they are related to large-scale differences in precipitation [4]. They will be further investigated in Sect. 3.1 and Sect. 4.2 .

\section{Materials and methods}

\subsection{Data}

We employ gridded time series data provided by the MERRA IAU 2D atmospheric single-level diagnostics [39]. Our main focus lies on the low-level atmospheric circulation, which is represented by the two-component wind field $\mathbf{v}_{i}(t)=\left(u_{i}(t), v_{i}(t)\right)$ at $850 \mathrm{hPa}$. Here, $u_{i}(t)$ is the zonal component of the wind field and $v_{i}(t)$ the meridional component. Additionally, the geopotential height at $250 \mathrm{hPa}$ and at $850 \mathrm{hPa}$, the total surface precipitation, and the wind field at $250 \mathrm{hPa}$ are obtained from the MERRA reanalysis. All these data sets are provided on a rectangular grid with a latitudinal resolution of $\Delta \lambda=\frac{1}{2}^{\circ}$ and a longitudinal resolution $\Delta \Phi=\frac{2}{3}^{\circ}$.

The MERRA reanalysis data thus have a considerably higher resolution than the NCEP/NCAR data (daily, $2.5^{\circ} \cdot 2.5^{\circ}$ ) used in the original study of the active and break SAMS phases $[4,40]$.

The streamflow networks studied in the following were computed on a large map section spanning $0^{\circ} \mathrm{W}-$ $110^{\circ} \mathrm{W} ; 70^{\circ} \mathrm{S}-25^{\circ} \mathrm{N}$ and thus comprising $N=33,366$ nodes. To minimize biases due to boundary effects of these spatially embedded networks, we choose a region that is substantially larger than the South American continent and the area we are interested in.

In all figures shown below, the resulting network measures are cropped to the same map section that is used for the geopotential height and precipitation: $20^{\circ} \mathrm{W}-$ $90^{\circ} \mathrm{W} ; 60^{\circ} \mathrm{S}-20^{\circ} \mathrm{N}$. All data sets employed here have daily temporal resolution and span the time interval from 1985 to 2010. For our analysis, we focus on the core monsoon season from December through February (DJF). 


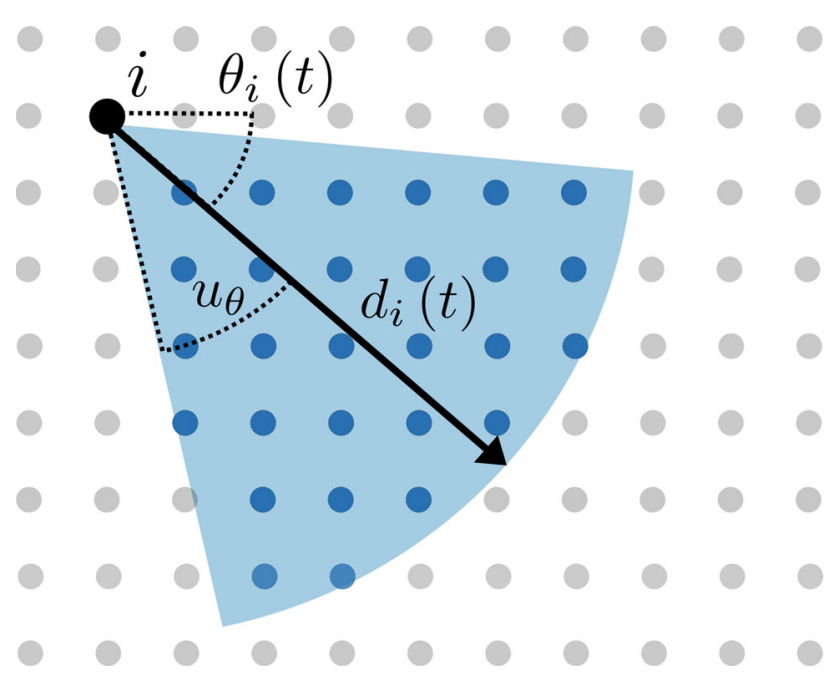

Fig. 2 Schematic of the streamflow network approach, as introduced in [33]. The nodes in dark blue inside the shaded circle section are considered to be reachable by the wind of node $i$ at time $t$. The radius of the circle section $d_{i}(t)$ is defined as in Eq. 2. The black arrow indicating the direction of the circle section has the same direction as the wind vector $\mathbf{v}$. The travel time $T$ and the angle uncertainty $u_{\theta}$ are parameters of the network that need to be suitably chosen

\subsection{Streamflow networks}

In this study, we make use of directed, unweighted complex networks. Such networks are defined by a set of $N$ nodes and $m$ directed edges connecting the nodes. All of these nodes are spatially embedded, representing a single grid cell and its climatic variability. A common representation of the network edges is the adjacency matrix

$A_{i j}= \begin{cases}1 & \text { if there is an edge directed from node } j \text { to } i \\ 0 & \text { otherwise. }\end{cases}$

It is our aim to construct networks whose topological properties provide a representation of the spatial coupling structure of the observed wind data. We do this by employing the recently introduced streamflow network method [33]. In contrast to other climate network approaches that build on similarity measures like the Pearson correlation coefficient, streamflow networks focus on the actual local wind flow. The aim is to link nodes along wind paths (see Fig. 2 for a sketch of this approach): For a single node $i$ at a single time step $t$, we define a circle section with the radius $d_{i}(t)$, the direction $\theta_{i}(t)=\measuredangle\left(\mathbf{v}_{i}(t)\right)$ and $2 \cdot u_{\theta}$ as its central angle. The distance is defined as

$$
d_{i}(t)=\left|\mathbf{v}_{i}(t)\right| \cdot T+u_{d_{i}}(\lambda)
$$

The added uncertainty $u_{d_{i}}(\lambda)=0.5\left(d_{m}+d_{z}\left(\lambda_{i}\right)\right)$ is defined as the average of the distance of node $i$ to its next neighbor in meridional direction $d_{m}$ and zonal direction $d_{z}\left(\lambda_{i}\right)$. This is done to ensure that there are no dead ends, and to emphasize on connected paths through the network.

Next, we apply this procedure to the complete time series of all nodes. In this way we obtain hit counts $h_{i j}$ of how often node $j$ was reached by wind of node $i$ during the entire study period. These hit counts are approximately normally distributed [33]. To judge whether observed hit counts are statistically significant, for each node $i$ we compute $N_{\text {stat }}$ surrogate hit counts $\eta_{i j}^{(k)}$. These surrogates use a velocity that is randomly drawn from the time series of node $i$ and a direction drawn from an uniform distribution over the circle. The mean $\mu_{\eta, i j}$ and standard deviation $\sigma_{\eta, i j}$ of the surrogates provide us with a natural significance threshold for the hit counts $h_{i j}$. The adjacency matrix of the streamflow network is then defined as

$$
A_{i j}= \begin{cases}1 & \text { if } h_{i j}>\mu_{\eta, i j}+n \cdot \sigma_{\eta, i j} \quad \text { with } n \in \mathbb{N} \\ 0 & \text { otherwise }\end{cases}
$$

Streamflow networks exhibit four parameters: The travel time $T$ and angle uncertainty $u_{\theta}$ are proportional to the link density $\rho$ of the resulting network [33]. In order to ensure a network with enough links to exhibit interesting features, but not too many links for the network to get close to be fully connected, the travel time $T$ is set to $1 \mathrm{~d}$ and the angle uncertainty to $\pi / 6$. This results in link densities between $\rho \approx 0.02$ and $\rho \approx 0.03$ for the networks presented in this study. The number of surrogates $N_{\text {stat }}$ is chosen to be 200 , because we found empirically that using more surrogates only has a minimal influence on the resulting network measures. The significance parameter $n$ is set to 2 . This correspondents to a $95.5 \%$ significance level, assuming a normal distribution. For a more detailed discussion of the network parameters of streamflow networks, please refer to [33].

\subsection{Topological network measures}

To investigate the topology of the constructed networks, we use several different network measures. The simplest of them is connectivity, an area-adjusted degree centrality. The out- and in-area weighted connectivity (OAWC/IAWC) [41] are defined as

$$
\begin{aligned}
\mathrm{IAWC}_{i} & =\frac{\sum_{j=1}^{N} A_{i j} \cos \lambda_{j}}{\sum_{j=1}^{N} \cos \lambda_{j}} \\
\mathrm{OAWC}_{i} & =\frac{\sum_{j=1}^{N} A_{j i} \cos \lambda_{j}}{\sum_{j=1}^{N} \cos \lambda_{j}} .
\end{aligned}
$$

and add an additional latitude-dependent weight to the degree. The difference between out- and in-area weighted connectivity

$$
D_{i}=\mathrm{OAWC}_{i}-\mathrm{IAWC}_{i}
$$




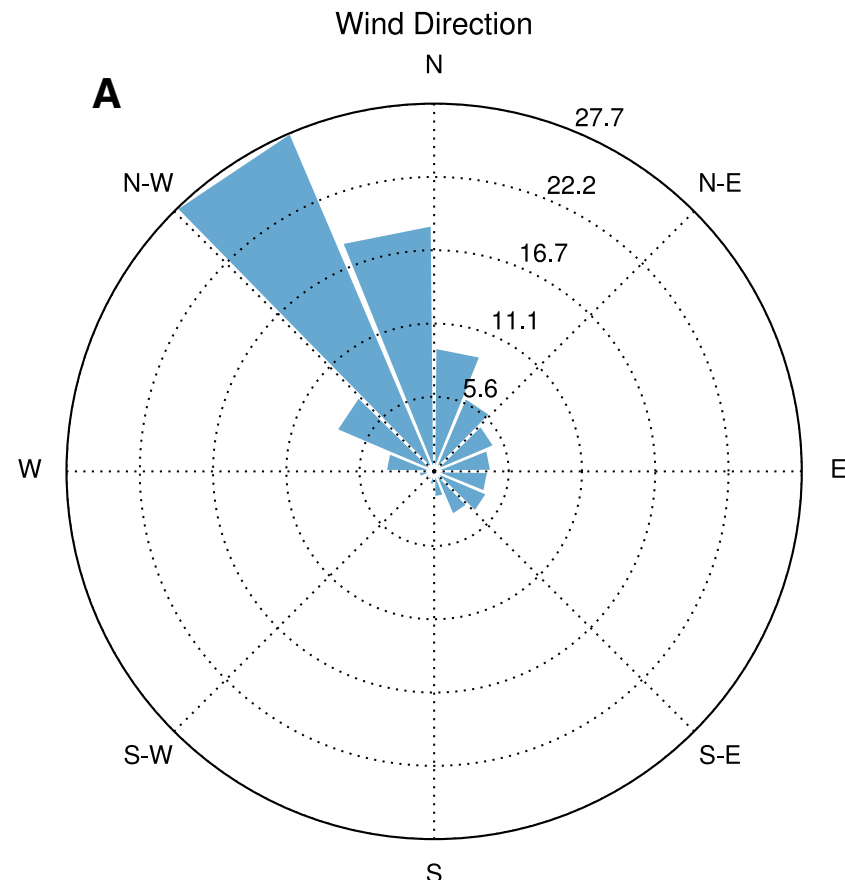

Fig. 3 Histograms of wind directions at $850 \mathrm{hPa}$ in the Bolivian districts of Beni and Santa Cruz $\left(13^{\circ}-18^{\circ} \mathrm{S}, 59^{\circ}-\right.$ $65^{\circ} \mathrm{W}$, see Fig. 1). While the normal wind direction (A) exhibits only one broad regime, the direction of the anomaly wind vector field (B) exhibits two distinct regimes: the east-

enables us to uncover possible directional asymmetries in the network, such as sinks and sources of the corresponding streamflow.

The proposed streamflow networks emphasize paths through the network, which we associate with important wind paths in the atmospheric circulation pattern. A network measure suitable to expose nodes which are crucial for the overall path structure is the betweenness centrality. It relies on the concept of shortest (or geodesic) paths. The geodesic distance $d_{i j}$ is the length of the geodesic paths (i.e., the smallest number of edges) between two nodes $i$ and $j$ of the network. The betweenness centrality

$$
B_{i}=\sum_{j k} \frac{n_{j k}^{(i)}}{g_{j k}}
$$

quantifies the relative number of geodesic paths through a given node $i: n_{j k}^{(i)}$ is the number of geodesic paths between nodes $j$ and $k$ running through $i$ and $g_{j k}$ is total number of geodesic paths between nodes $j$ and $k$ (note that more than one such shortest path may exist) [42].

Spatially embedded networks exhibit boundary effects by the choice of the map section [43]. At the case at hand, boundary effects of the degree, OAWC and IAWC of streamflow networks can be mitigated by choosing a larger map section, because streamflow networks possess a maximum link distance. By extending the map

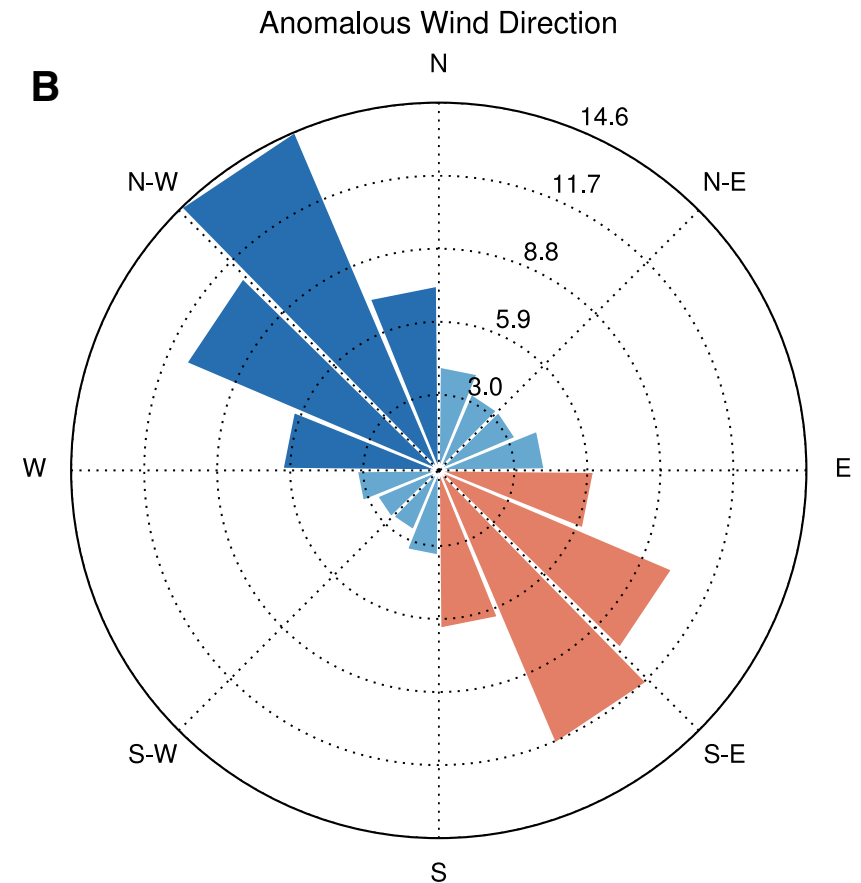

erly regime (orange) and the westerly regime (dark blue). The anomaly wind vector field was computed by removing the mean componentwise. Figure 4 shows the corresponding wind fields. The wind direction is, by convention, the direction the wind originates from

section by $20^{\circ}$ of longitude, we add about $2000 \mathrm{~km}$ at $20^{\circ} \mathrm{S}$ or about $1000 \mathrm{~km}$ at $60^{\circ} \mathrm{S}$ in zonal direction to the map section. Low-level winds have a typical velocity of $\mathcal{O}\left(1 \mathrm{~ms}^{-1}-10 \mathrm{~ms}^{-1}\right)$. When using a travel time $T=1 \mathrm{~d}$ this yields a maximum link distance of approximately $900 \mathrm{~km}$. The spatial embedding is, therefore, only relevant for the OAWC and IAWC for strong winds in high latitudes. Unfortunately, path-based network measures are affected by spatial embedding in a more complex fashion. While we can thus not mitigate these effects completely, we minimize them by choosing larger map sections as well.

In this study we investigate the spatiotemporal characteristics of different phases of the DJF seasons of the SAMS. We will focus on intraseasonal differences between active and break monsoon phases on the one hand, and interannual differences between El Niño and La Niña phases on the other hand. We chose to present both normal network measures and network measure anomalies. For this purpose, we computed a reference streamflow network representing the DJF climatology with the same parameter set that we use for all other networks. For each node-based network measure $X$, its anomalies follow as the difference between the network measure of the corresponding phase $X_{i}^{\text {phase }}$, and the network measure of the DJF-network $X_{i}^{\mathrm{DJF}}$ : $\hat{X}_{i}=X_{i}^{\text {phase }}-X_{i}^{\mathrm{DJF}}$. The difference between two phases is the same for anomalies and normal network measures, since we do not rescale the anomalies: $X_{i}^{\text {Diff }}=$ $X_{i}^{\text {phase } 1}-X_{i}^{\text {phase } 2}=\hat{X}_{i}^{\text {Diff }}$. 
Fig. 4 Wind fields at $850 \mathrm{hPa}$ during active (westerly, $\mathbf{A}$ and $\mathbf{C}$ ) and break (easterly, $\mathbf{B}$ and $\mathbf{D}$ ) regimes for the DJF season. The arrows indicate the wind direction and strength. The top row (A, B) uses the regular meridional and zonal wind components during the active and break phases, respectively. The bottom row $\mathbf{C}, \mathbf{D}$ shows anomalous wind fields, which were computed by removing the seasonal mean componentwise from the wind vector. The absolute value of the wind is color-coded in all subfigures. The bottom row panels show the anomalous absolute value, which was computed by removing the mean from the absolute value and performing a one-sample t-test. Only absolute value anomalies at a $95 \%$ significance level are shown. During the active phase the South American Low-Level Jet (SALLJ) is visibly enhanced. Between the active and the break phases the direction of the anomalous wind vectors is reversed
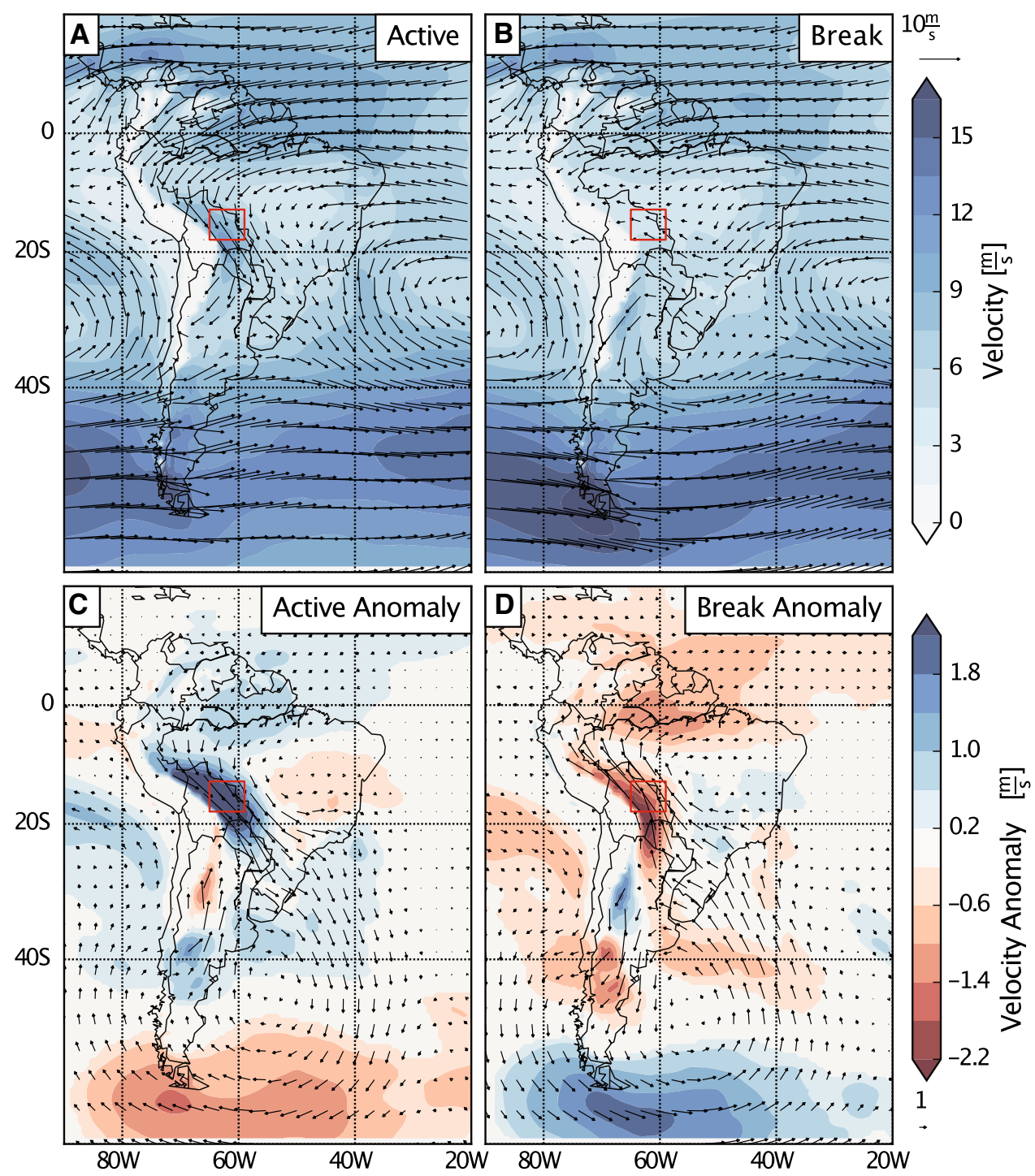

\section{Results}

\subsection{Intraseasonal variability of the SAMS caused by active and break phases}

In the original study on active and break phases of the SAMS, the reference region used to distinguish the two phases was placed in Rondônia [4]. When investigating the SAMS with the MERRA data set, it became apparent that there are differences to the NCEP/NCAR data set used by [4]. Whereas the NCEP/NCAR data set exhibits an overall westerly wind regime in Rondônia, the MERRA data set exhibits a broad northerly wind regime in Rondônia. We, therefore, shift the reference region southward by $4^{\circ}$ to $\left(13^{\circ}-18^{\circ} \mathrm{S}, 59^{\circ}-65^{\circ} \mathrm{W}\right)$ to retain a narrower, westerly wind distribution in the reference region with the MERRA data set as well. This area corresponds roughly to the Bolivian districts Beni and Santa Cruz. Figure 1 shows both, the location of the Rondônia reference region and the new reference region in Beni and Santa Cruz (BSC). A more detailed discussion of the choice of the reference region can be found in the Appendix A.

When removing the seasonal mean from the wind field componentwise, the distribution of the wind direction within the reference region splits into two distinct regimes (see Fig. 3). As introduced in Sect. 1.1, these can be identified with active and break phases of the monsoon. The active regime exhibits an north-westerly wind direction $([\pi / 2, \pi]$, when east is identified with the angle zero). The break regime exhibits the opposing south-easterly wind direction $([-\pi / 2,0])$. Based on these two wind regimes, we can subdivide the time series into an active (westerly) time series and a break (easterly) time series. A time step is considered to be in the active or break regime, respectively, if $75 \%$ or more of the nodes in BSC exhibit an anomaly wind direction of the corresponding direction interval. This classification is robust to small changes of this percent value. The robustness is further increased by choosing the reference region in BSC instead of in Rondônia as well. 

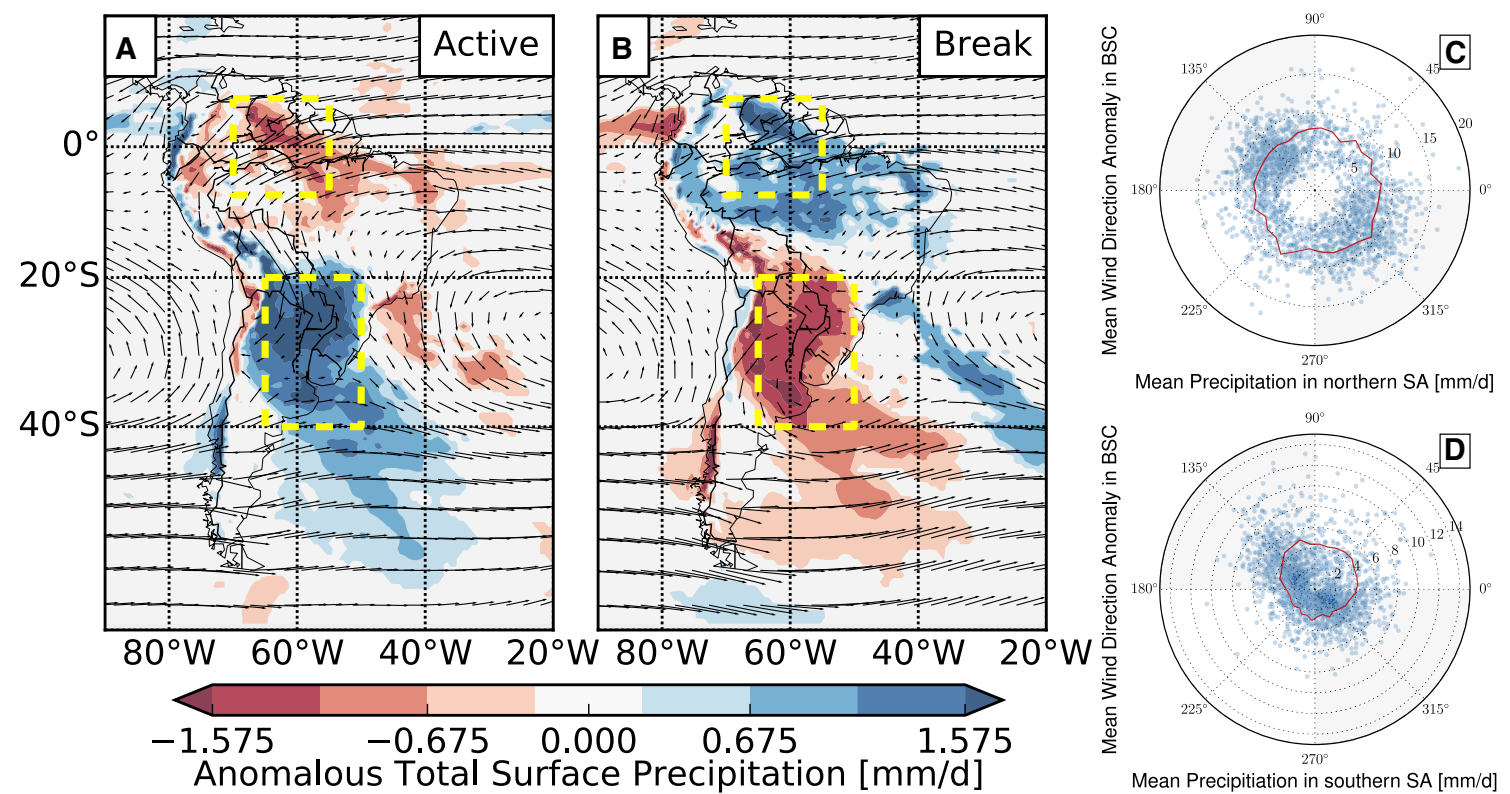

Fig. 5 Anomalous total surface precipitation of the active (A) and the break (B) regimes based on MERRA. The anomalies are computed with respect to the DJF climatology. Statistical significance was determined with a onesample t-test, and non-significant $(p>0.05)$ anomalies are shown in white. The active phase is characterized by enhanced precipitation in southern Brazil, SESA and Bolivia, whereas the break phase exhibits strong precipitation in Venezuela, Peru and the Amazon basin. The rose plots in the right panel show the mean daily precipitation of all nodes within the yellow, dashed rectangles in northern South America (C) and southern South America (D),

For the examined time series from 1985 to $2010,26 \%$ of the days during the DJF seasons are classified as active and $21 \%$ of the days of the DJF seasons are classified as break. Time steps for which the wind direction is between these two regimes are not further investigated.

\subsubsection{Wind and precipitation composites}

Figure 4 shows the wind fields for both regimes. The active regime exhibits a stronger cross-equatorial flux with faster winds along the eastern slopes of the Andes. During the break phase easterly winds from southern Brazil flow towards Paraguay and Bolivia. The strongest absolute winds are the year-long strong westerly winds in the southern Atlantic and Pacific. Those exhibit a south-westerly direction in Patagonia during the active phase and a westerly to north-west-westerly direction during the break phase. The anomaly wind field of the westerly regime is characterized by strong north-westerly winds close to the eastern slopes of the Andes, indicating a substantially strengthened SALLJ. These north-westerly winds lead into a cyclone south of Uruguay over Argentina and the adjacent Atlantic ocean. The anomalous wind direction of the easterly regime is almost exactly reversed, with a suppressed SALLJ and the cyclone replaced by an anticyclone.

depending on the wind direction in Beni and Santa Cruz. The wind direction in Beni and Santa Cruz is the circular mean of the wind direction of all nodes within this reference region (see Fig. 1). Note, that the wind direction, per convention, is the direction the wind originates from. In southern South America, highest precipitation occurs when the region of Beni and Santa Cruz exhibits a northwesterly wind direction, whereas less precipitation occurs for southeasterly anomalies. The red, solid line indicates the mean precipitation of all data within the corresponding 1/32 of the whole circle

All the anomalies shown were subject to a one-sample t-test. Non-significant anomalies $(p>0.05)$ are not shown.

The role of the wind regimes to classify the activity of the SAMS becomes clear when investigating the precipitation anomalies of the two regimes (Fig. 5). During the active phase there is substantially more precipitation in SESA and southern Brazil. While the daily mean precipitation is about $3 \mathrm{~mm}$ when there are predominately easterly winds in BSC, it increases to $4.1 \mathrm{~mm}$ when they are predominately westerly winds in BSC. During the break phase there is more precipitation in the Amazon and northern South America. While the absolute differences in precipitation in these regions are similar to the differences induced in SESA, the relative differences are smaller. The spatial distribution of precipitation shows that the westerly and easterly anomaly wind regimes have a strong impact on the activity of the SAMS. In particular for this reason, these monsoon phases provide an ideal application for wind networks.

These results on wind and precipitation composites for the active and break phases are, although derived from distinct data sets, qualitatively inline with the earlier results of [4]. 



Out-Area Weighted Connectivity Anomaly

Fig. 6 Out-area weighted connectivity (OAWC, see Eq. 5) of wind networks computed separately for the active and break phase of the SAMS, as well as the difference between these phases, are shown in the top row. The bottom row shows anomaly measures that were calculated by subtract-

\subsubsection{Network results}

Streamflow networks for the active and break phases were computed with the parameter set introduced in Sect. 2.2. The link density $\rho$ of the networks differs in a range between 0.023 and 0.028 . The network of the full DJF season exhibits the largest value of $\rho$. The outdegree and, therefore, the link density depends directly on the wind velocity (see Eq. 2) and, in a more complex way, on the variance of the wind direction: In general, larger variances of the wind direction tend to result ing the network measures of a streamflow network of the complete DJF season. The OAWC is dominated by the strong eastward winds in the south of South America. Key differences between both phases can be found along the eastern slopes of the Andes

in larger link densities. While the mean velocity of all nodes and all time steps is fairly similar for all subsets and the full time series, the variance of the wind direction is naturally lower when we consider only subsets of the time series, based on the wind direction of the reference region $\mathrm{BSC}$.

When comparing climate networks whose construction is based on similarity measures (such as correlation coefficients), it is common practice to choose the construction parameters in a way that keeps the link density constant [16]. We select here a different approach 
for the following reason: Our construction method is directly related to the underlying wind field, and in such a case, at least, the link density is just another network measure. To be sure, however, we tested the adjustment of the link density for the computation of the network measure anomalies. By choosing a larger value for the statistical parameter $n$ (see Sect. 2.2), we increase the significance threshold and can thereby decrease the link density to a value that lies between the ones of the networks computed for the different phases while keeping the other parameters constant. The resulting, corrected anomalies for the path-based network measures are almost identical to the non-corrected anomalies (not shown), which can be understood as follows: As mentioned above, path-based measures like betweenness and closeness are based on shortest paths through the network. A larger variance of the wind direction adds only relatively few shortest paths to the network, and path-based measures are relatively resilient to small changes of $\rho$. This also supports our association of important wind paths with path-based measures of streamflow wind networks (see Sect. 4.1). Please refer to Fig. 1 for some of the geographical regions referenced in the following results.

The spatial distributions of the OAWC of the networks computed for the active and break phases are, overall, quite similar (top row of Fig. 6): largest values can be observed in the south, where strong eastward winds dominate. Furthermore, both phases exhibit a west-east asymmetry in high latitudes due to the spatial embedding. The OAWC displays the largest difference between the active and the break phase in central and southern South America. The eastern slopes of the Andes exhibit a stronger OAWC for the active phase in Venezuela, Peru, Bolivia, Paraguay and southern Argentina. Furthermore, the whole Argentinian coast exhibits a much larger OAWC during the active phase. The Amazon has higher OAWC values during the active phase as well. In contrast, the break phase exhibits substantially higher OAWC values in northern Argentina in the Gran Chaco area, as well as in eastern and central Brazil. The network measure anomalies (bottom row of Fig. 6) are qualitatively similar to the difference between both phases, which implies that the DJFnetwork used to calculate the anomalies exhibits values in the middle between the extreme cases (active and break phases). It is most apparent that the break phase exhibits strongly negative anomalies along the eastern slopes of the Andes.

For both phases, the difference of out- and in-area weighted connectivity $D$ (see Fig. 7) exhibits the largest values in southern South America and over the subtropical Atlantic ocean. During the active phase there is a small band of positive difference in LLA and more prominent areas of positive $D$ in NBP, where the network of the break phase exhibits $D$ values close to zero. The break phase exhibits strongly positive $D$ values in the Gran Chaco area, where the active phase on the other hand boasts negative $D$ values. During the active phase, there are positive $D$ values in Patagonia, which is even more apparent in the anomaly measure. Fur-
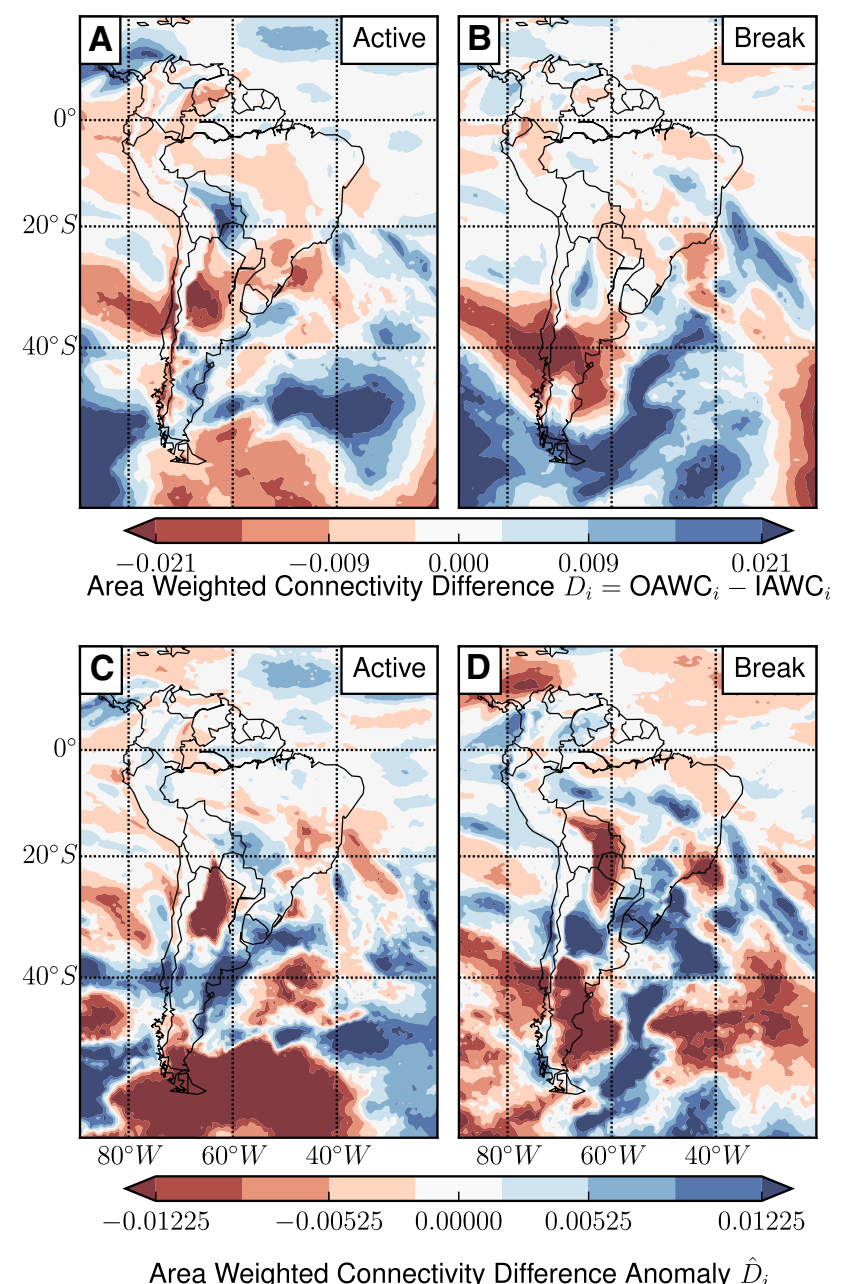

Fig. 7 Difference between out- and in-area weighted connectivity $D$ (see Eq. 6) of wind networks for the active and break phase of the SAMS. Like in the other figures showing network measures, the anomaly measures were calculated by subtracting the network measures of a streamflow network for the complete DJF season. The SALLJ area in Bolivia and Paraguay exhibits high values during the active phase. This area of high values is shifted southward during the break phase

thermore, there is an area with a strongly negative $D$ north of it.

The betweenness centrality over the South American continent (Fig. 8) exhibits large values along the eastern slopes of the Andes. This band is much longer and stronger during the active phase. Especially the betweenness anomaly (bottom row of Fig. 8) shows strongly negative values along the eastern slopes of the Andes during the break phase. We observe only few mid- or large-sized areas on the South American continent, where the break phase exhibits larger betweenness values than the active phase: the Guyana highlands, eastern Brazil, and the Gran Chaco area. 

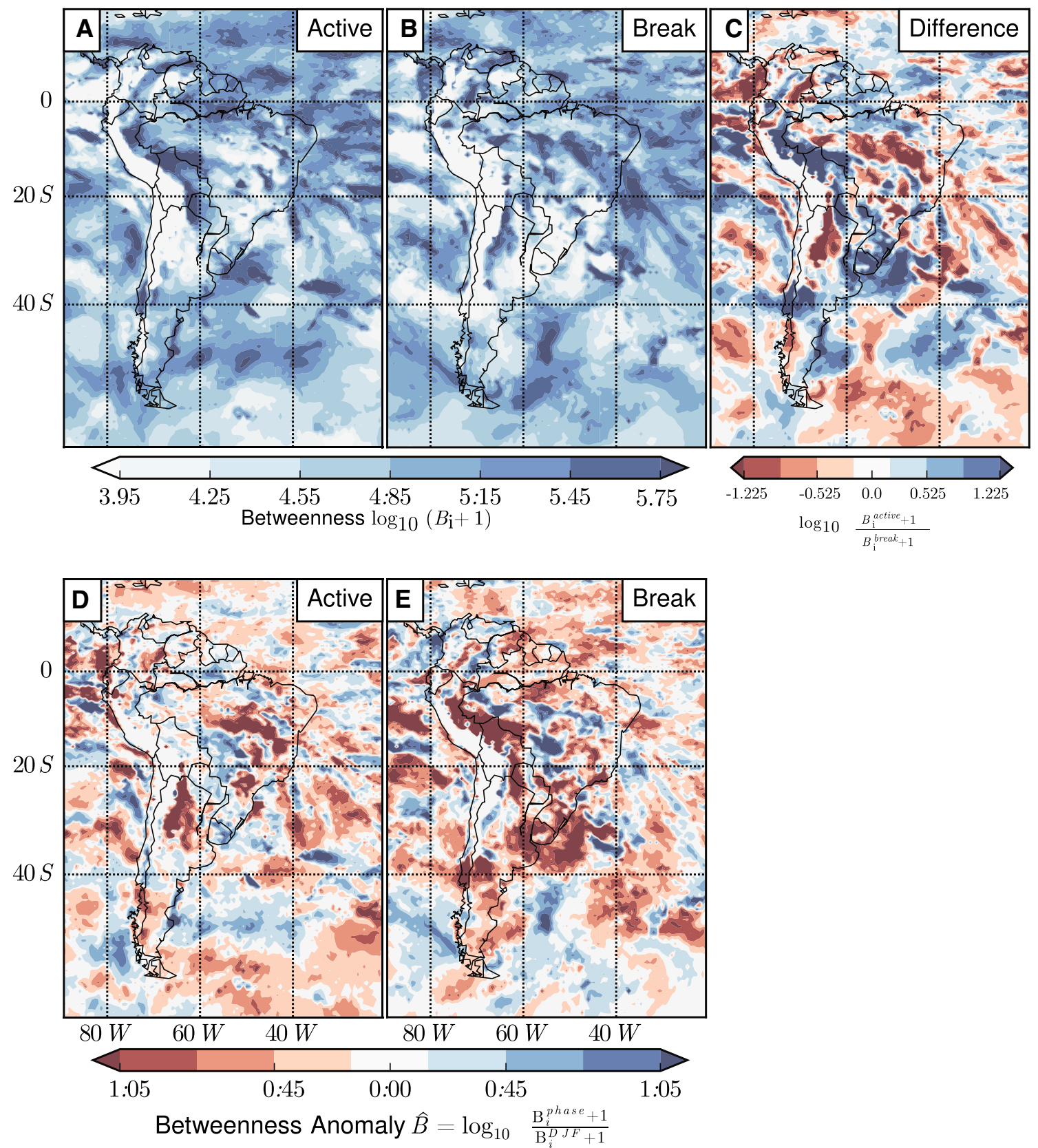

Fig. 8 Betweenness centrality (see Eq. 7) of wind networks of the active and break phase and the difference between them. During the active phase the SALLJ along the eastern slopes of the Andes is much more pronounced. As the range

\subsubsection{Geopotential height composites}

In addition to the network analysis and the investigation of precipitation anomalies (see Sect. 1.1), geopotential height composites also provide information about the state of the atmospheric circulation during the active and break phases (see Figs. 9 and 11 ). These composites were formed by averaging the geopotential height of the corresponding time series of the active and break phases, and subtracting the climatology for DJF. between the minimum and maximum betweenness of a network is quite large and scales with the number of nodes [42], it is common to show the logarithm of the betweenness. The anomaly is shown as the difference of logarithms as well

The geopotential height at $850 \mathrm{hPa}$ (GPH850) exhibits negative (positive) anomalies along the eastern slopes of the Andes during the active (break) phase, starting in Bolivia and extending further southward. There is a local minimum (maximum) in the Gran Chaco area, indicating the enhanced (suppressed) Northern Argentinean Low (NAL) during the active (break) phase. The largest differences can be found in an anomalous cyclone over the southern Atlantic ocean east of Argentina, which extends into the aforementioned pressure anomaly at the eastern Andean slopes. The 


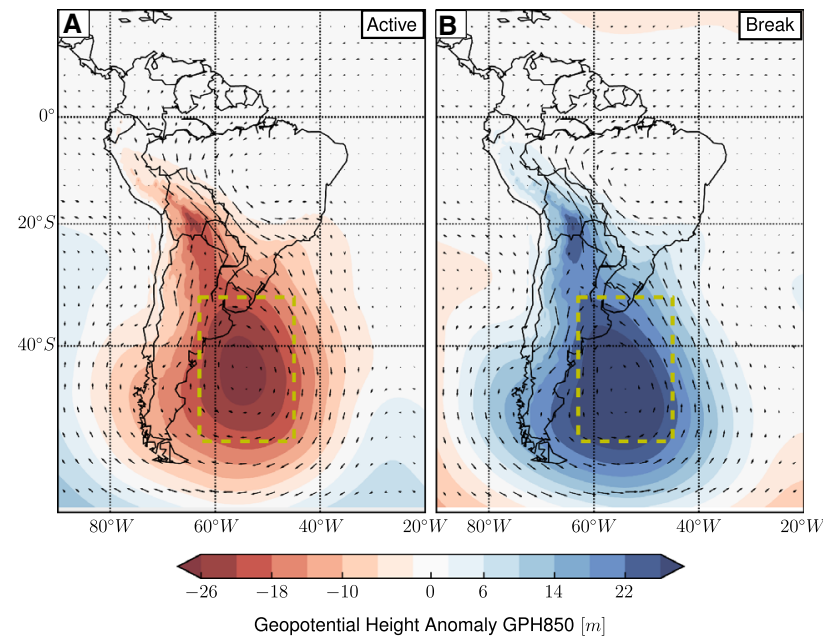

Fig. 9 Geopotential height at $850 \mathrm{hPa}$ during the active and break phase. The anomalies were calculated by subtracting the DJF-mean and are significant at a 95\% level. Black arrows represent the mean anomaly wind field at $850 \mathrm{hPa}$ during the corresponding phase. The yellow, dashed line marks the area with the largest differences that is referred to in the text

low-pressure cell that can be observed east of southern Argentina results in strong south-westerly winds in southern Argentina and over the adjacent Atlantic ocean during the active phase. In contrast, the wind direction during the break phase is westerly to northwesterly.
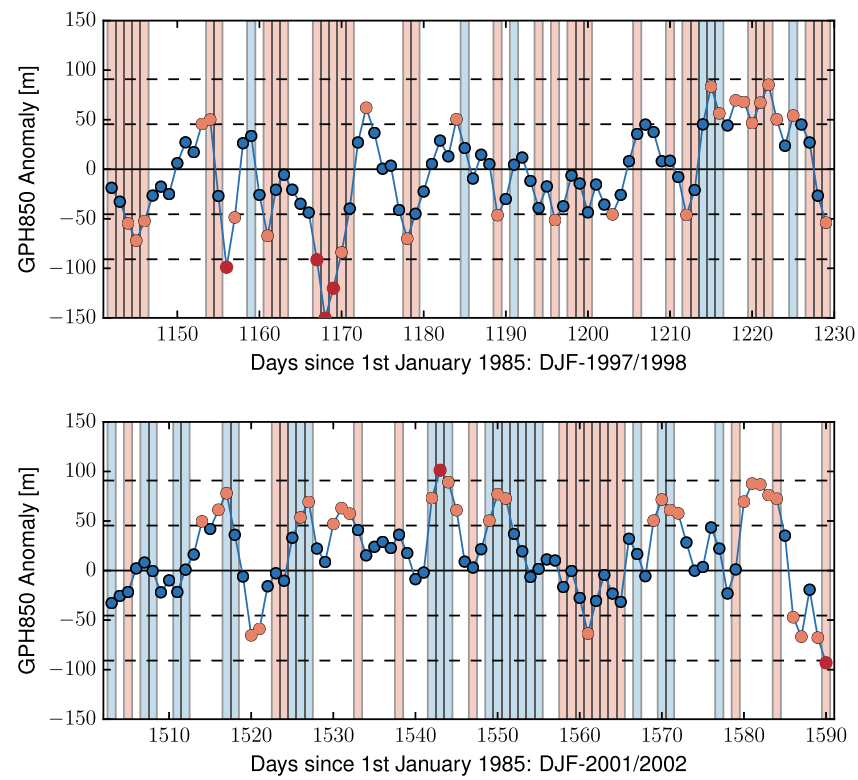

Fig. 10 Spatial mean of the anomaly of the geopotential height at $850 \mathrm{hPa}$ (GPH850) in the southern Atlantic (refer to Fig. 9 for the exact region). To demonstrate the intraseasonal evolution of the GPH850 and the relation to the active and break phases, 4 years of the time series have been chosen at random. The horizontal dashed lines
As this anomalous low/high pressure system in the subtropical Atlantic is one of the most distinctive differences between the active and break phase, it is subject to further investigation. Figure 10 shows the intraseasonal evolution of the GPH850 in relation to the active and break phases. The GPH850 anomaly varies around zero in a close-to-periodic fashion, with active events generally occurring more often during negative anomalies and break events occurring more often during positive anomalies. The mean of the GPH850 during active phases is GPH850 active $=-22.7 \pm 44.5 \mathrm{~m}$, compared to GPH850 break $=25.6 \pm 42 \mathrm{~m}$ during break phases. Here, the empirical standard deviation of all GPH850 values that belong to the corresponding phase is used to estimate the uncertainty of the mean. There is an overlap between the GPH850 values of the regimes; however, this overlap does not include the mean values of the opposing phase.

The average length of an active phase is $2.52 \pm$ 1.8 days and the length of break phases is $2.26 \pm$ 1.77 days. However, as already recognizable in Fig. 10, there are many occasions when only single days interrupt the active phase. If one would choose to loosen the criterion or smoothen the wind direction signal, it would most likely result in much longer average lengths.

The upper-level circulation is primarily characterized by Rossby Waves, the Westerlies, and the Bolivian high. The geopotential height anomalies at $250 \mathrm{hPa}$ (see Fig. 11) reveal opposing patterns of Rossby wave train composition for the two composites: The active phase exhibits negative anomalies over southern South America and positive anomalies in southern Brazil. Cen-
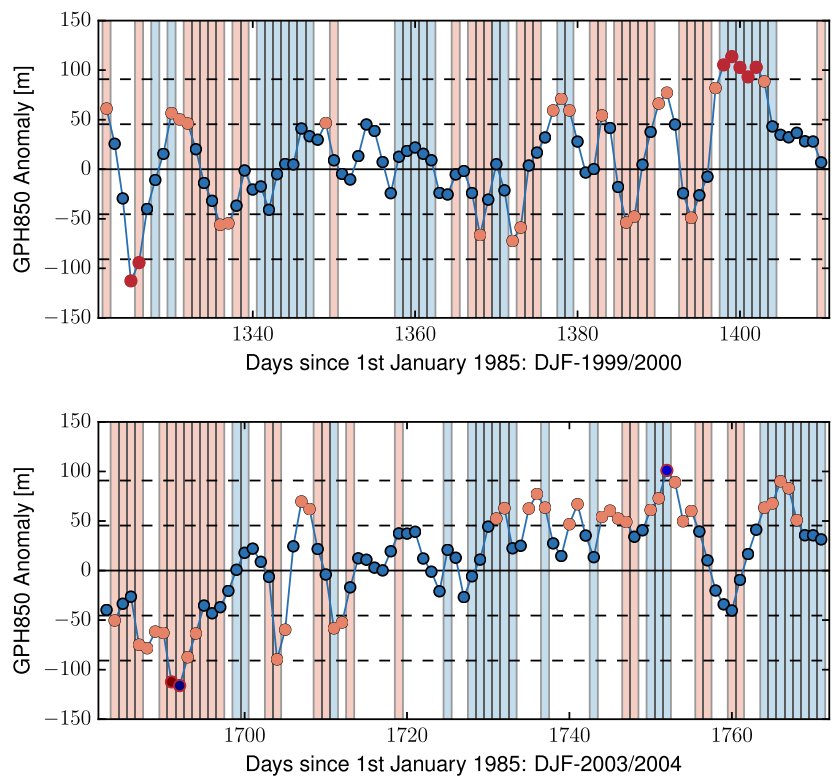

mark multiples of the empirical standard deviation $\sigma_{\mathrm{GPH} 850}$. Spatially averaged GPH850 values are marked in orange if $|\mathrm{GPH} 850| \geq \sigma_{\mathrm{GPH} 850}$, and in red if $|\mathrm{GPH} 850| \geq 2 \cdot \sigma_{\mathrm{GPH} 850}$. In the background, all days that belong to the active phase are colored in light red and all days that are part of the break phase are colored in light blue 


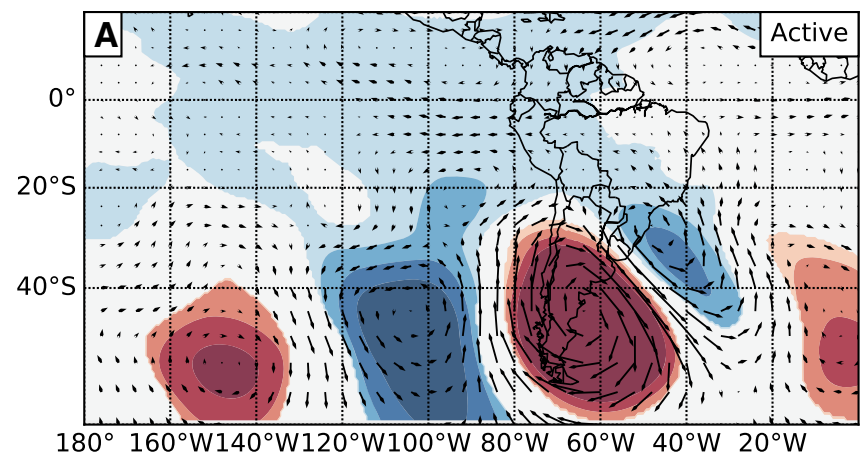

$-26.25$

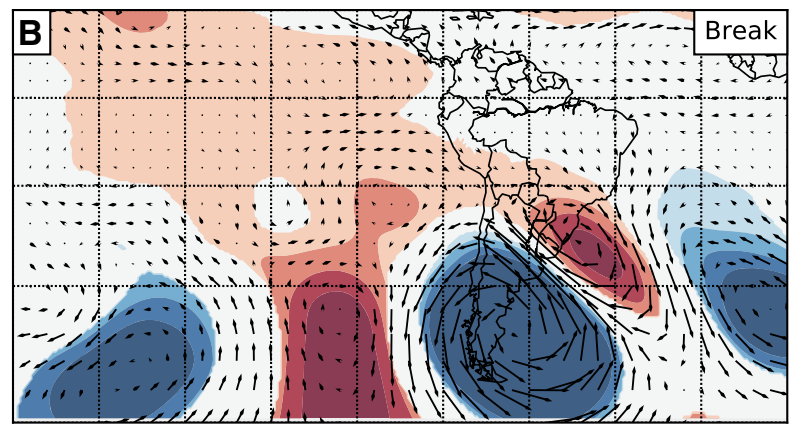

$180^{\circ} 160^{\circ} \mathrm{W} 140^{\circ} \mathrm{W} 120^{\circ} \mathrm{W} 100^{\circ} \mathrm{W} 80^{\circ} \mathrm{W} 60^{\circ} \mathrm{W} 40^{\circ} \mathrm{W} 20^{\circ} \mathrm{W}$

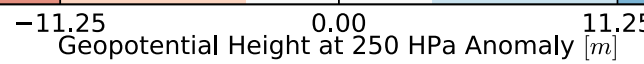

26.25

Fig. 11 Geopotential height anomaly at $250 \mathrm{hPa}$ of the active (A) and break (B) phase of the SAMS, calculated by removing the DJF-mean from time series and averaging over all time steps of the respective phase. Black arrows are proportional in length to the anomalous wind field at $250 \mathrm{hPa}$ of the corresponding phase
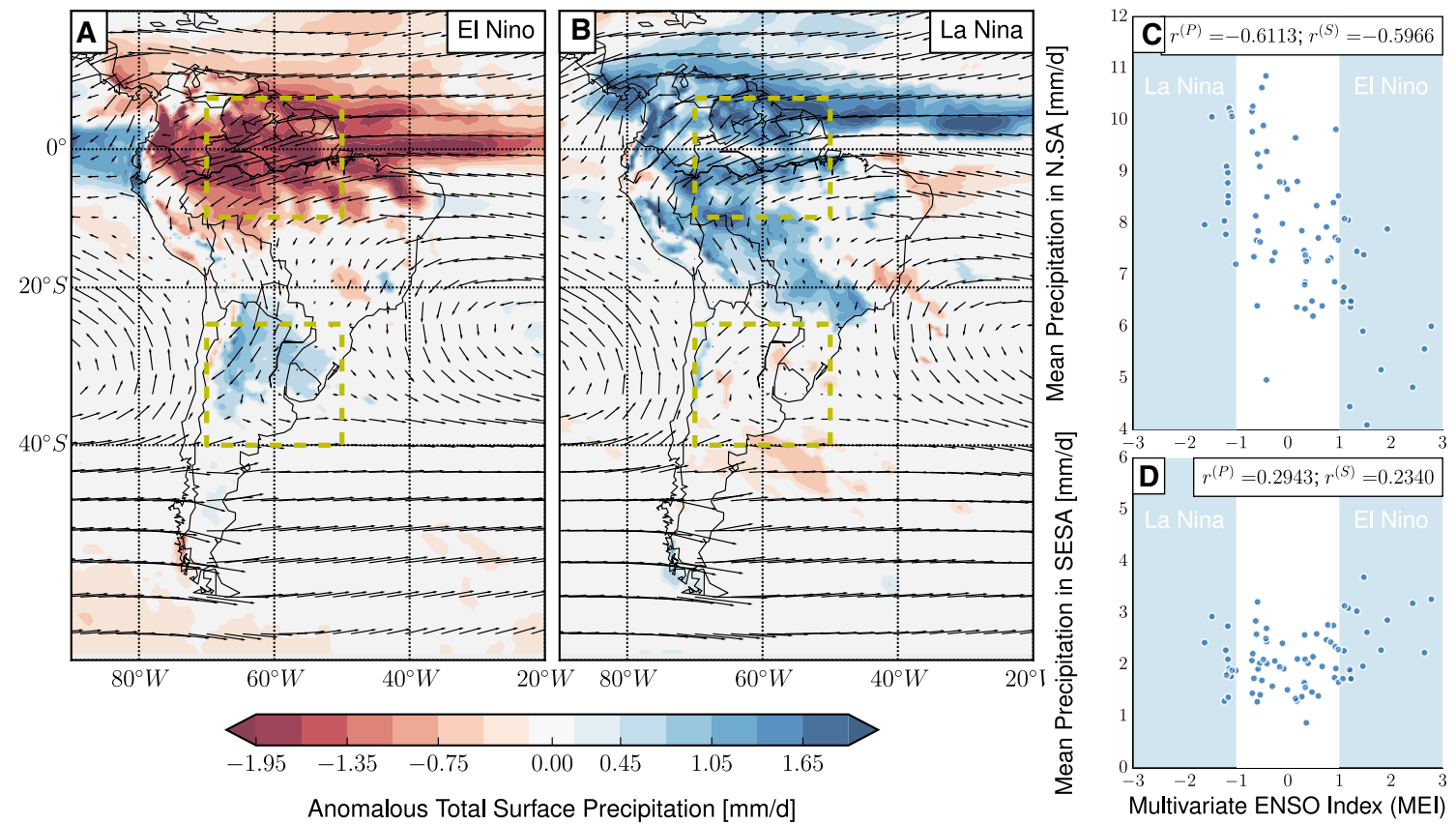

Fig. 12 Anomalous total surface precipitation during El Niño (A) and La Niña events (B). The anomalies were computed with respect to the DJF climatology. Regions with non-significant $(p>0.05)$ anomalies, as calculated with a one-sample t-test, are shown in white. The black arrows encode the mean magnitude and direction of the wind field during El Niño or La Niña events, respectively. For the correlation analysis mean daily precipitation for each month

tral and northern South America exhibit slightly positive anomalies. In contrast, the break phase has positive anomalies at the southern South America, negative anomalies in southern Brazil, and slightly negative values in central South America. The position and the sign of the largest GPH250 anomalies in southern South America correspond well to the GPH850 anomalies. was computed separately for northern South America (C) and southern South America (D) (marked by yellow, dashed lines, respectively). The correlation between this mean precipitation value and the monthly Multivariate ENSO Index (MEI) was estimated with the Pearson correlation coefficient $r^{(P)}$ and Spearman's rank correlation coefficient $r^{(S)}$

\subsection{Interannual variability of the SAMS caused by the ENSO}

The El Niño Southern Oscillation (ENSO) is one of the most important sources of interannual variation for the SAMS [6]. Figure 12 shows the precipitation anomalies of El Niño and La Niña events. There is a negative correlation between the Multivariate ENSO Index (MEI, [44]) and the precipitation in northern South Amer- 

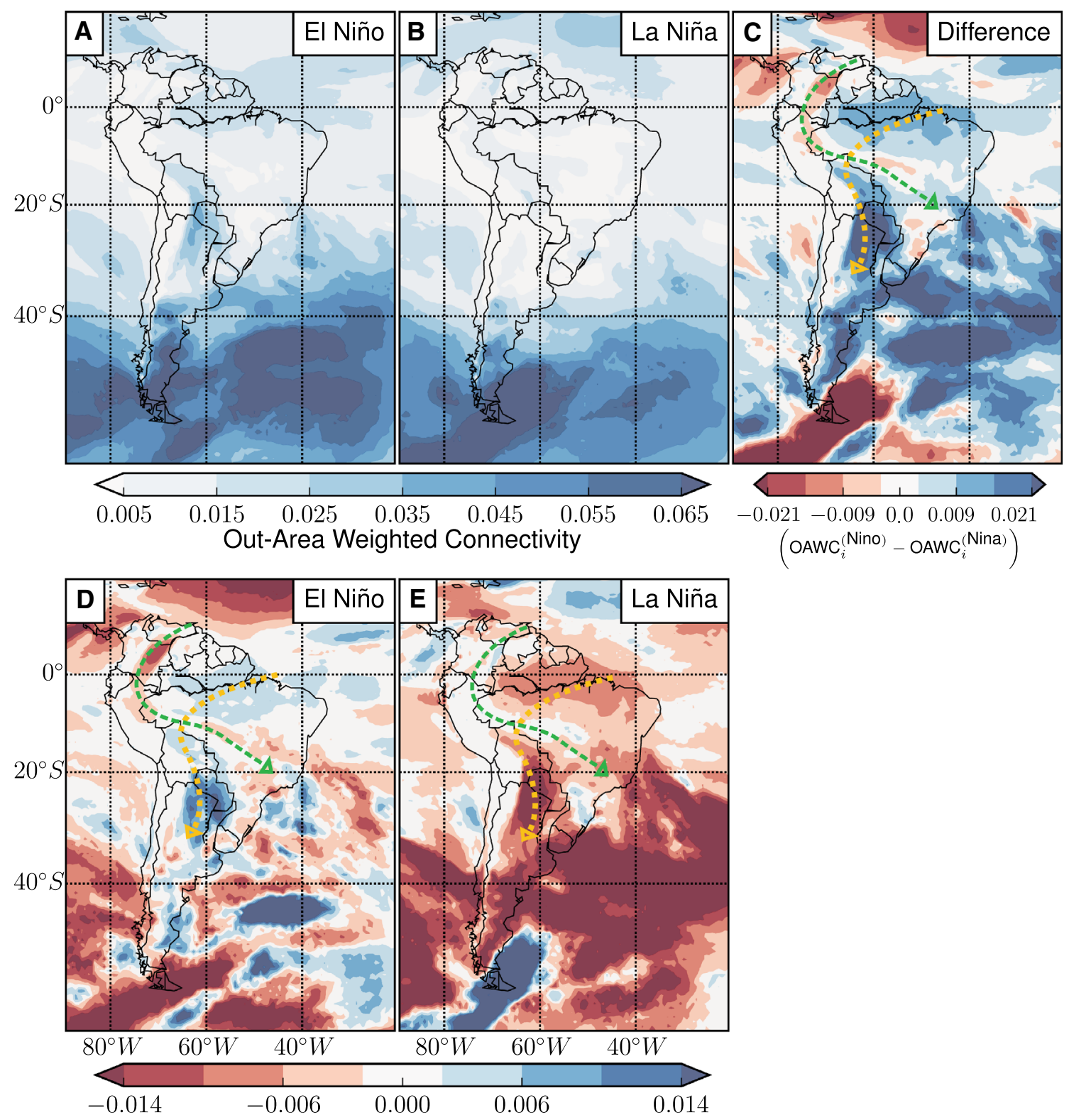

Out-Area Weighted Connectivity Anomaly

Fig. 13 Out-area weighted connectivity (OAWC, see Eq. 5) of streamflow wind networks during El Niño and La Niña phases. The top row shows the normal network measures and the difference between the two ENSO phases. The bottom row shows anomaly OAWC which are, as before, computed as the differences between the OAWC of the respective phase and the OAWC of the complete DJF season. The El Niño network exhibits larger values for most parts of the map. Especially noteworthy is the large OAWC

ica, including most parts of the Amazon. In contrast, average precipitation in SESA is larger during El Niño. However, there is no clear correlation between the precipitation in SESA and the MEI as the Pearson coefficient is only $r^{(P)}=0.29$ and the Spearman coefficient is $\rho^{(S)}=0.23$. The low-level circulation is affected by during El Niño phases at the eastern slopes of the central Andes in Bolivia, Paraguay and northern Argentina. The La Niña network exhibits slightly larger OAWC along the eastern slopes of the northern Andes. The dominant enhanced large-scale wind path during El Niño conditions is marked in yellow, whereas the weakened wind path is shown green. Conversely, the yellow wind path is attenuated and the green wind path enhanced during La Niña events

the ENSO as well, as studies suggest a strengthening of the SALLJ during El Niño events [45].

For our investigation of the variability of the low-level circulation to the ENSO, we subdivide the wind field time series in a positive ENSO (El Niño) and a negative ENSO (La Niña) part according to the Multivariate 

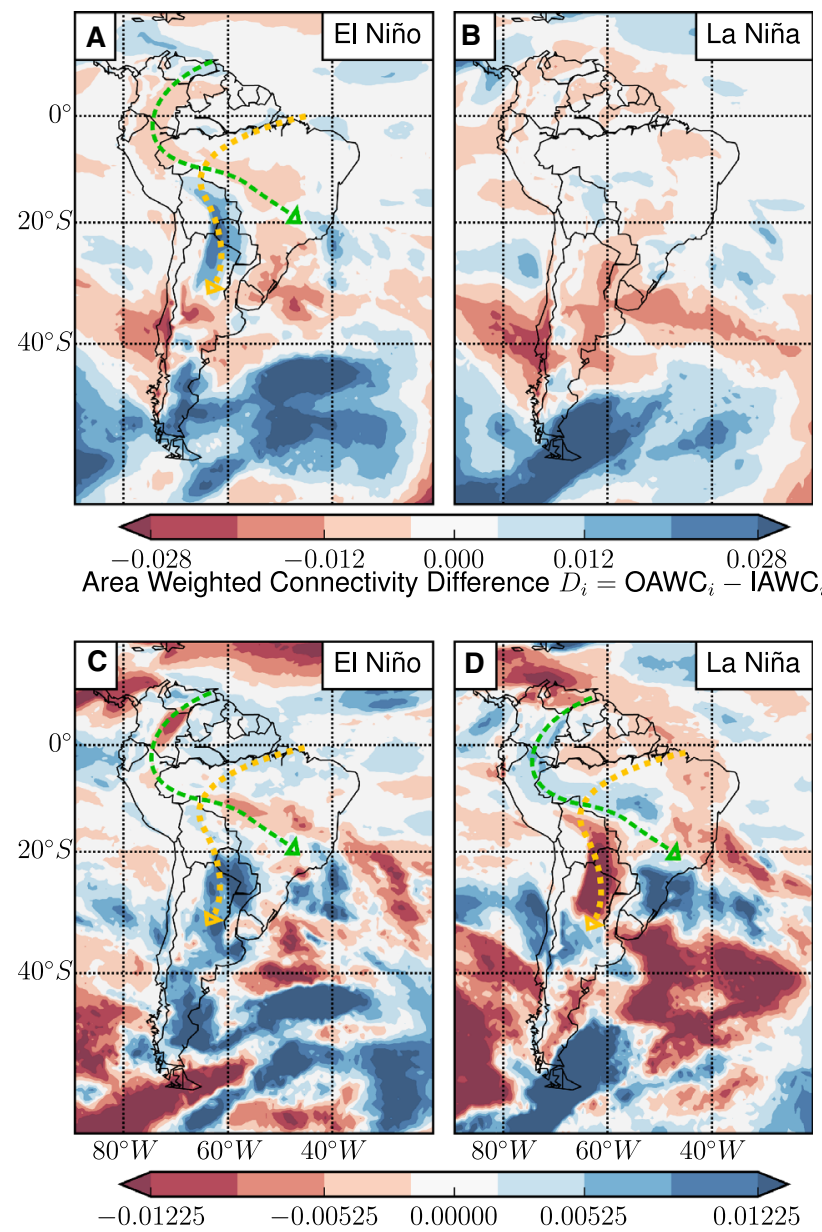

Area Weighted Connectivity Difference Anomaly $\hat{D}_{i}$

Fig. 14 Difference of out- and in-area weighted connectivity $D$ (see Eq. 6) of the El Niño and La Niña phases. The anomalies were calculated with respect to a network of the complete DJF season. Note the strongly negative anomalies along the eastern slopes of the Andes in Bolivia and northern Argentina during La Niña events. As in Fig. 13, the dominant large-scale wind paths are shown
ENSO Index (MEI) [44]. When MEI $\geq 1$ a month is considered to be an El Niño month and when MEI $\leq-1$ a month is considered to be a La Niña month. Given the data set that spans from 1985 to 2010 , restricted to the austral summer, this results in $17 \mathrm{El} \mathrm{Niño} \mathrm{and} 13$ La Niña months.

The network of the El Niño phase exhibits a larger link density than the La Niña network for otherwise constant parameters $\left(\rho_{\text {Niño }}=2.6 \%\right.$ and $\left.\rho_{\text {Niño }}=2.3 \%\right)$. On the South American continent, the OAWC is distinctively larger during El Niño events along the eastern slopes of the central Andes in Argentina, Paraguay and Bolivia. The El Niño anomaly exhibits distinctly negative values at the slopes of the northern Andes, but positive anomalies in the Amazon. Contrarily, the La Niña network exhibits larger OAWC values on the eastern slopes of the Andes in Venezuela and Peru (see Fig. 13) and strongly negative anomalies in Argentina, Paraguay and the Amazon.

The area weighted connectivity difference $D$ exhibits key differences between the ENSO types at the eastern slopes of the Andes as well (Fig. 14). The El Niño network exhibits negative values both in the normal and the anomaly measure in Llanos and south of it, where the La Niña network exhibits positive $D$ anomalies. These positive anomalies extend eastward to central Brazil. In NBP and Gran Chaco the El Niño network exhibits positive $D$ values with positive anomalies extending southward until the southern tip of South America. Contrarily, the La Niña network only shows small area weighted connectivity difference in these regions, but exhibits strongly negative Anomalies in NBP and Gran Chaco. These differences, combined with those of the OAWC described before show, as is best visible in Figs. 13 and 14 directly, different wind dominant wind paths in the respective ENSO phases.
Fig. 15 Histograms of wind directions at $850 \mathrm{hPa}$ in the Brazilian state of Rondônia $\left(9^{\circ}-13^{\circ} \mathrm{S}\right.$, $\left.60^{\circ}-64^{\circ} \mathrm{W}\right)$. This is the same as Fig. 3 but with a northward shifted reference region that is identical to the study of [4]

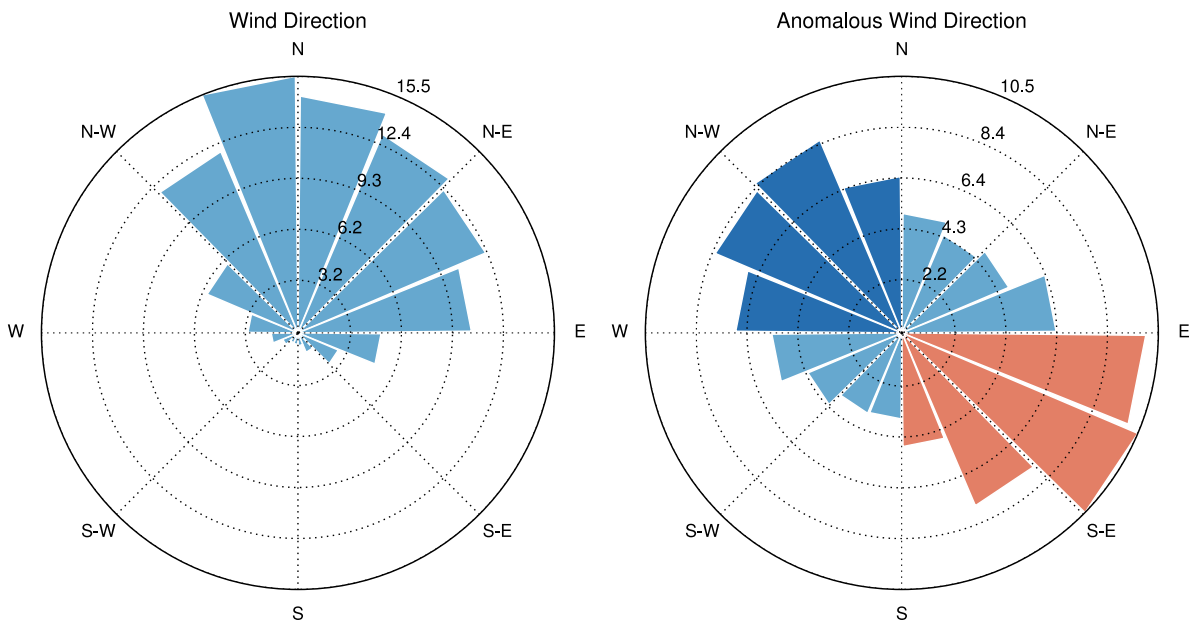




\section{Discussion}

\subsection{Climatological interpretation of network measures}

In Sect. 2.3 we introduced various topological network measures. These encode the spatiotemporal coupling structure of the atmospheric flow in different ways. The OAWC is directly related to the absolute value of the wind of a given node. Therefore, this measure itself only provides us with limited additional information compared to the wind field itself, but comparing the OAWC of different time regimes can still give us further insights into the strength of the wind field during these regimes.

The difference of OAWC and IAWC encodes information about directional asymmetries of the network. Even though much of this difference at the edges of the map section is caused by boundary effects [43], it also contains valuable information about the wind field itself. Large, positive values of the difference were found at the eastern slopes of the Andes in an area which is typically associated with the SALLJ. The winds leading into the area are slower than the winds of the SALLJ itself, which, therefore, has a larger OAWC. In addition, their direction is deflected by the Andes in a rather narrow area, resulting in even lower IAWC values in the SALLJ area. This results in large positive values of the area weighted connectivity difference. It can, therefore, serve as a measure of the variability of the SALLJ.

The difference of OAWC and IAWC can also provide information about sources and sinks of the wind field. This is visible, for example, in Fig. 7 between $20^{\circ} \mathrm{S}$ and $40^{\circ} \mathrm{S}$, where we observe low OAWC, but large IAWC, and directly south of it we find nodes which exhibit high OAWC, but low IAWC. This encodes the information about northward propagating frontal systems that transport cold, dry air to South America from the South during so-called cold surges [46-48].

The streamflow network method is designed to emphasize paths in the network: Due to the local nature of the construction method, we associate paths in the network with climatological wind paths. The betweenness centrality is a measure of the fraction of shortest network paths running through a node. It, therefore, emphasizes areas which are crucial for the overall structure of the wind field. This holds especially true for narrow, jet-like structures that connect different parts of the network, like the SALLJ.

\subsection{Active and break phases of the SAMS}

\subsubsection{Cross-equatorial flow and low-level jet}

We subdivided the wind field time series based on a small reference region in northern Bolivia (BSC, see Fig. 1). Although the strength of the anomaly wind fields for the active and break monsoon phases weakens the further away from BSC one goes, both network types exhibit large differences across the South Amer- ican continent and the adjacent oceans in all network measures that were investigated.

There is hardly any cross equatorial flow in the break phase. The investigation of the OAWC and betweenness shows that both, the trade winds toward and across the Amazon, and the southward flow along the slopes of the Andes, are much stronger during the active phase. This flow along the eastern slopes of the central Andes constitutes the SALLJ. The betweenness and area weighted connectivity difference $D$, furthermore, suggest Llanos as an important pathway for the cross-equatorial flow of the active phases. However, only the No-Chaco Jet is enhanced during the active phase, as there are negative anomalies in the Gran Chaco area. The break phases exhibit the opposite behavior, as shown by all network measures and the wind field itself: the SALLJ is strongly suppressed, as noticeable by the absence of large betweenness and $D$ values along the eastern slopes of the Andes, but especially by distinctly high, negative anomalies of all network measures in these areas. The SALLJ is the key feature for transporting moisture from the Amazon to SESA [34], and the enhanced SALLJ can thus be considered one of the main reasons of the strong precipitation difference between both regimes (see Fig. 5). The generally positive anomalies of the geopotential height at $250 \mathrm{hPa}$ over Bolivia additionally suggest a strengthening of the Bolivian high.

The break phase exhibits strong southward winds in the Gran Chaco area, which are strongly suppressed during the active phases. These are highlighted by differences of all shown network measures as well. However, these are not indicating a Chaco Jet, as the SALLJ in Bolivia is still strongly suppressed during the break phase. This wind system, which is sometimes referred to as Argentinian low-level jet [49], is instead directly related to the anomalous high/low pressure systems forming over the subtropical Atlantic ocean that are further investigated below (Sect. 4.2.2).

\subsubsection{Large-scale atmospheric circulation in Southern South America}

One of the most distinct differences in the low-level atmosphere between the active and the break phase of the SAMS is the striking difference in the geopotential height at $850 \mathrm{hPa}$, showing pronounced cyclonic (anticyclonic) activity over southern South America and the adjacent Atlantic ocean during the active (break) phase. This pressure anomaly is related to a Rossby wave train that is most apparent in the geopotential height at $250 \mathrm{hPa}$. This wave train, a longitudinal oscillation of low- and high-pressure anomalies, originates from the southern Pacific ocean and propagates eastward across the southern part of the South American continent $[19,47]$. The further analysis of the mean GPH850 over the subtropical Atlantic indicates the substantial relationship between the GPH850 over the subtropical Atlantic and the active and break monsoon phases. 
During the active phase, the negative GPH850 anomalies extend further north as well, showing an intensified Northern Argentinian Low (NAL) that further amplifies the moisture flux from the Amazon to SESA during this phase. The negative GPH850 anomalies are forming an anomalous cyclone in the south Atlantic during the active phase that results in more northwards winds originating from Patagonia. These are especially highlighted by the concise pattern of large OAWC and $D$. The anomalous cyclone also causes northward anomaly winds in the Gran Chaco area. These in turn result in the suppressed Chaco Jet that is visible in the networks.

Contrarily, the break phase exhibits an anomalous anticyclone that accelerates southwards winds in the Gran Chaco area but overall suppresses the SALLJ. This is notably apparent in the anomalous betweenness field. The most concise patterns of the betweenness of the break network are the strongly negative anomalies along the eastern slopes of the Andes and the strongly negative anomalies in the center of the anticyclone over the Atlantic ocean south of Uruguay.

The described differences in the geopotential height fields between active and break monsoon phases suggest that the alternation between the two phases is modulated by the Rossby wave train. In addition to the spatial composite maps, this hypothesis is strongly supported by the approximately periodic switching between active and break phases, which happens in concert with alternating low and high pressure anomalies over the subtropical Atlantic ocean (see Fig. 10), caused by the eastward propagation of the Rossby wave train.

We note that both lower and upper level pressure configurations during the active phase strikingly resemble corresponding geopotential height anomalies studied in the context of extreme precipitation events in SESA and at the eastern slopes of the central Andes $[19,47]$. This suggests a close connection between the active monsoon phase and extreme event occurrences associated with cold surges which propagate northward into subtropical South America [46], modulated by the Rossby wave train.

\subsection{Impact of ENSO on SAMS low-level circulation}

The networks presented above were computed with wind data that include all El Niño and La Niño events during austral summer between 1985 and 2010. The SALLJ is enhanced during the El Niño phase as shown by the OAWC and betweenness centrality. This is in accordance with case observations that were made during El Niño events in 1998 and 2003 [35,50]. The network results presented here comprise data from a multitude of El Niño events and thus support the claim that the enhanced SALLJ is a general effect of El Niño, which did not only happen in single years. Especially the more southward Chaco Jet exhibits a much larger OAWC, $D$ and betweenness during El Niño events. The eastward No-Chaco Jet is less affected by the ENSO, which is agreement with the precipitation differences (see Fig. 12): while SESA, which is typically more affected by the Chaco Jet, exhibits slightly enhanced precipitation, southeast and central-west Brazil, which are more affected by No-Chaco Jets, exhibit positive precipitation anomalies during La Niña.

On a large scale, the dominant wind pathway from the tropics to the subtropics is shifted and rotated during positive and negative ENSO anomalies. This is suggested by the described differences between the ENSO network measures in Llanos, along the Amazon river and east of the central Andes: while the low-level flow during El Niño events is dominated by trade winds that flow toward the South American continent in zonal direction and are then channeled into a strong SALLJ with Chaco Jet characteristics, the low-level flow during La Niña events exhibits stronger cross-equatorial flow along the slopes of the Andes in northern South America, which is subsequently channeled into a less strong No-Chaco SALLJ. These flow paths are marked in the corresponding network figures (green and yellow dashed lines in Figs. 13 and 14 ).

The comparison of the subsets of the time series based on the MEI and the active and break regime shows that the occurrence of active phases is relatively independent from the ENSO. The frequency of active time steps is only marginally different during El Niño and La Niña months. However, break phases occur less often during El Niño events (13\% during El Niño events, $23 \%$ during La Niña). This is conceivable, as the El Niño events enhance the SALLJ which results in less easterly anomaly winds in the reference region used to distinguish the active and break phase.

\section{Conclusion}

We have analyzed the spatiotemporal circulation characteristics of the South American Monsoon System (SAMS) in terms of intraseasonal variability associated with the active and break monsoon phases, as well as in terms of interannual variability associated with the El Niño Southern Oscillation (ENSO). Our analysis is based on high-resolution data provided by NASA's Modern Era Retrospective-Analysis for Research and Applications. By combining composite analyses of the anomalies of wind, precipitation and geopotential height fields with the recently introduced streamflow wind networks, we were able to reveal how each of these phases influences the low-level circulation of the SAMS. The streamflow network approach is able to unveil the crucial differences between the active and break phase of the SAMS, but also between El Niño and La Niña conditions. The constructed streamflow networks have revealed the dominant wind pathways of the monsoonal circulation. They are particularly responsive to associated changes in the South American Low-Level Jet (SALLJ), which is the most important low-level moisture transport system of the SAMS.

Our main findings can be summarized as follows: 
1. The low-level circulation of the active monsoon phase is characterized by a strong cross-equatorial flow along the eastern slopes of the Andes, a strongly enhanced, southeastward-directed South American Low-Level Jet, and southerly winds over southern South America. While the Low-Level Jet is distinctly strong in Peru, Bolivia and Paraguay, it is suppressed in the Gran Chaco Area. The active monsoon phase is associated with an anomalous cyclone at low atmospheric levels over the Atlantic ocean south of Uruguay. The low-level circulation of the break monsoon phase is characterized by a pattern opposing the one observed for the active phase. In particular, the SALLJ is strongly suppressed and the anomalous cyclone over the subtropical Atlantic ocean is replaced by an anomalous anti-cyclone.

2. The opposing circulation patterns for the active and break monsoon phases occur in concert with approximately periodic oscillations between low and high pressure anomalies at $850 \mathrm{hPa}$ over the subtropical Atlantic ocean. These are connected to a Rossby wave train emanating from the southern Pacific ocean that is visible at $250 \mathrm{hPa}$ height. We thus infer that this Rossby wave train is the modulator of the alternations between active and break phases of the South American monsoon.

3. The dominant low-level wind pathways, and thus also the most important moisture transport routes, are strongly affected by ENSO: During El Niño events, the Chaco Jet (a southward extension of the SALLJ) is substantially enhanced, leading to above average precipitation in southeastern South America, while the cross-equatorial flow in northern South America is suppressed. These differences are part of a large-scale re-organization of the dominant wind paths, which is modulated by the ENSO: For El Niño conditions, the main wind path is directed westward along the Amazon river and closely follows the slopes of the central Andes southward to the Gran Chaco area. For La Niña conditions, this pathway is considerably shifted northward and rotated counterclockwise, leading to an enhanced cross-equatorial flow over northern South America, together with an enhanced eastward flow toward the subtropics.

These results corroborate also the results of the prior studies on the South American Monsoon System and show that the streamflow network approach is useful. Therefore, in future applications, it can be applied in other contexts, less well understood system, where it could then also reveal more new meteorological insights.

Acknowledgements This paper was developed within the scope of the IRTG 1740/TRP 2015/50122-0, funded by the DFG/FAPESP. The authors thank the German Federal Ministry of Education and Research and the Land Brandenburg for supporting this project by providing resources on the high performance computer system at the Potsdam Institute for Climate Impact Research. NB acknowledges funding by the Volkswagen foundation. JK acknowledges funding by the Russian Ministry of Science and Education Agreement No. 075-15-2020-808.

Funding Open Access funding enabled and organized by Projekt DEAL.

\section{Author contribution statement}

The study was designed by MG and NB. MG carried out the analysis. All authors discussed the results. MG drafted the manuscript. All authors edited and discussed the manuscript.

Data availability The data used in this study is publicly available from NASA's MERRA reanalysis project.

Open Access This article is licensed under a Creative Commons Attribution 4.0 International License, which permits use, sharing, adaptation, distribution and reproduction in any medium or format, as long as you give appropriate credit to the original author(s) and the source, provide a link to the Creative Commons licence, and indicate if changes were made. The images or other third party material in this article are included in the article's Creative Commons licence, unless indicated otherwise in a credit line to the material. If material is not included in the article's Creative Commons licence and your intended use is not permitted by statutory regulation or exceeds the permitted use, you will need to obtain permission directly from the copyright holder. To view a copy of this licence, visit http://creativecomm ons.org/licenses/by/4.0/.

\section{A Appendix: Reference region for active and break phases}

This study uses a reference region in Beni and Santa Cruz (BSC) in Bolivia to distinguish between the active and break phases of the SAMS. This region is shifted southward by $4^{\circ}$ latitude from the reference region in Rondônia $\left(9^{\circ}-13^{\circ} \mathrm{S}, 60^{\circ}-64^{\circ} \mathrm{W}\right)$ that was used in the initial description of the active and break SAMS phases by [4]. In our research we use a different data source, MERRA, whereas [4] used NCEP/NCAR data. While the NCEP/NCAR wind field in Rondônia exhibits an overall westerly wind regime in Rondônia, the MERRA wind field exhibits a broader, northerly wind regime in Rondônia during DJF (see Fig. 15). Nonetheless, the anomaly wind field of the MERRA data in Rondônia exhibits a westerly and an easterly regime as well. By shifting the reference region southward to BSC, we obtain an overall westerly wind direction distribution (Fig. 3). Furthermore, active phases occur more often and are on average $0.5 \mathrm{~d}$ longer when BSC instead of Rondônia is used as reference region. In Sect. 3.1.3 we found that the geopotential height at $850 \mathrm{hPa}$ in the southern Atlantic is connected to the active and break phases as well. The difference between the mean geopotential height at $850 \mathrm{hPa}$ in the southern Atlantic is larger when using $\mathrm{BSC}$ as the reference region $\left(\Delta \mathrm{GPH}_{850}=34.2 \mathrm{~m}\right.$ versus 
Table 1 Coincidence of the active phases determined with different reference regions. This coincidence is calculated as $C_{A B}=\frac{|A \cap B|}{|A|}$, where $A$ and $B$ denote the sets of numbered time steps that are part of the active regime for the corresponding reference region. $|A|$ is the amount of elements in the set $A$. As in general $|A| \neq|B|$, it follows that $C_{A B} \neq C_{B A}$. The reference regions are Beni and Santa Cruz (BSC) as used in this study, Rondônia (RON) as used in [4], as well as the regions obtained by shifting BSC further south-east (SE) and north-west (NW). Precise coordinates of the latter two regions, which only serve the purpose of testing robustness, are specified in Sect. A

\begin{tabular}{lllll}
\hline & BSC & RON & SE & NW \\
\hline Beni and Santa Cruz (BSC) & 1 & 0.49 & 0.69 & 0.72 \\
Rondônia (RON) & 0.71 & 1 & 0.52 & 0.80 \\
South-East (SE) & 0.90 & 0.47 & 1 & 0.70 \\
North-West (NW) & 0.78 & 0.60 & 0.58 & 1 \\
\hline
\end{tabular}

Table 2 Coincidence of the break regimes of different reference regions. The naming of the reference regions and the calculations follow those of Table 1

\begin{tabular}{lllll}
\hline & BSC & RON & SE & NW \\
\hline Beni and Santa Cruz (BSC) & 1 & 0.54 & 0.65 & 0.66 \\
Rondônia (RON) & 0.53 & 1 & 0.42 & 0.65 \\
South-East (SE) & 0.82 & 0.54 & 1 & 0.60 \\
North-West (NW) & 0.68 & 0.68 & 0.49 & 1 \\
\hline
\end{tabular}

$\left.\Delta \mathrm{GPH}_{850}=48.2 \mathrm{~m}\right)$. The $\Delta \mathrm{GPH}_{850}$ for the BSC reference region is larger than the standard deviation of the geopotential height in the southern Atlantic, $\sigma_{\mathrm{GPH} 850}=45.1 \mathrm{~m}$, whereas the $\Delta \mathrm{GPH}_{850}$ for the Rondônia region would be smaller than the standard deviation.

We tested the further robustness of the results by shifting the reference region $\mathrm{BSC}$ along the eastern slopes of the Andes in Bolivia. The north-western region (NW) $\left(15^{\circ}-\right.$ $\left.10^{\circ} \mathrm{S}, 69^{\circ}-63^{\circ}\right)$ and the south-eastern region $(\mathrm{SE})\left(21^{\circ}-\right.$ $\left.15^{\circ} \mathrm{S}, 62^{\circ}-56^{\circ} \mathrm{W}\right)$ induce active and break phases with a much larger coincidence to the studied phases with the reference region in $\mathrm{BSC}$ than to the phases with the reference region in Rondônia (see Tables 1 and 2 ). The values of $\Delta \mathrm{GPH}_{850}$ and the overall qualitative structure of the streamflow networks is very similar as well. The results are, therefore, robust to a shift of the BSC reference region along the north-west to south-east axis following the eastern slopes of the Andes.

\section{References}

1. P.J. Webster et al., Monsoons: Processes, predictability, and the prospects for prediction. J. Geophys. Res. 1978-2012(103), 14451-14510 (1998). https://doi.org/ 10.1029/97JC02719

2. K. Ramamurthy, Monsoon of india: Some aspects of the 'break' in the indian southwest monsoon during july and august. Forecasting Manual 1-57 No. IV 18.3, India Met. Dept. (1969)

3. M. Rajeevan, S. Gadgil, J. Bhate, Active and break spells of the Indian summer monsoon. J. Earth Syst. Sci. 119, 229-247 (2010). https://doi.org/10.1007/ s12040-010-0019-4
4. C. Jones, L.M.V. Carvalho, Active and break phases in the South American Monsoon System. J. Clim. 15, 905914 (2002). https://doi.org/10.1175/2008JCLI2249.1

5. J. Zhou, K.-M. Lau, Does a monsoon climate exist over South America? J. Clim. 11, 1020-1040 (1998)

6. C.R.M. Brant, B. Liebmann, The South American Monsoon System, in The Global Monsoon System: Research and Forecast, ed. by C.P. Chang (World Scientific, London, 2011), pp. 137-157

7. M.J. Rodwell, B.J. Hoskins, Subtropical anticyclones and summer monsoons. J. Clim. 14, 3192-3211 (2001)

8. J.A. Marengo, M.W. Douglas, P.L.S. Dias, The south american low-level jet east of the andes during the 1999 lba-trmm and lba-wet amc campaign. J. Geophys. Res. (2002). https://doi.org/10.1029/2001JD001188

9. J. Nogués-Paegle, K.C. Mo, Alternating wet and dry conditions over South America during summer. Month. Weather Rev. 125, 279-291 (1997)

10. J.A. Marengo, W.R. Soares, C. Saulo, M. Nicolini, Climatology of the low-level jet east of the andes as derived from the ncep-ncar reanalyses: Characteristics and temporal variability. J. Clim. 17, 2261-2280 (2004)

11. A.C. Saulo, M.E. Seluchi, M. Nicolini, A case study of a chaco low-level jet event. Month. Weather Rev. 132, 2669-2683 (2004). https://doi.org/10.1175/MWR2815. 1

12. M. Gelbrecht, N. Boers, J. Kurths, Phase coherence between precipitation in South America and rossby waves. Sci. Adv. 4, eaau3191 (2018)

13. T.L. Montini, C. Jones, L.M.V. Carvalho, The South American low-level jet: A new climatology, variability, and changes. J. Geophys. Res. 124, 1200-1218 (2019). https://doi.org/10.1029/2018JD029634

14. R.V. Andreoli et al., The influence of different el niño types on the South American rainfall. Int. J. Climatol. 37, 1374-1390 (2017). https://doi.org/10.1002/joc.4783

15. A. Tsonis, P. Roebber, The architecture of the climate network. Phys. A 333, 497-504 (2004) 
16. F.J. Donges, Y. Zou, N. Marwan, J. Kurths, Complex networks in climate dynamics. Eur. Phys. J. Spec. Top. 174, 157-179 (2009). https://doi.org/10.1140/ epjst/e2009-01098-2

17. N. Malik, B. Bookhagen, N. Marwan, J. Kurths, Analysis of spatial and temporal extreme monsoonal rainfall over South Asia using complex networks. Clim. Dyn. 39, 971-987 (2012). https://doi.org/10.1007/ s00382-011-1156-4

18. N. Boers, B. Bookhagen, N. Marwan, J. Kurths, J. Marengo, Complex networks identify spatial patterns of extreme rainfall events of the South American Monsoon System. Geophys. Res. Lett. 40, 4386-4392 (2013). https://doi.org/10.1002/grl.50681

19. N. Boers et al., Prediction of extreme floods in the eastern central andes based on a complex networks approach. Nat. Commun. 5, 5199 (2014)

20. N. Boers et al., Complex networks reveal global pattern of extreme-rainfall teleconnections. Nature 566, 373377 (2019). https://doi.org/10.1038/s41586-018-0872-x

21. S. Molnos et al., A network-based detection scheme for the jet stream core. Earth Syst. Dyn. 8, 75-89 (2017)

22. A.A. Tsonis, K.L. Swanson, Topology and predictability of el niño and la niña networks. Phys. Rev. Lett. 100, 228502 (2008). https://doi.org/10.1103/PhysRevLett. 100.228502

23. K. Yamasaki, A. Gozolchiani, S. Havlin, Climate networks around the globe are significantly affected by el niño. Phys. Rev. Lett. 100, 225801 (2008). https://doi. org/10.1103/PhysRevLett.100.228501

24. M. Wiedermann, A. Radebach, J.F. Donges, J. Kurths, R.V. Donner, A climate network-based index to discriminate different types of el niño and la niña. Geophys. Res. Lett. 43, 7176-7185 (2016). https://doi.org/ 10.1002/2016GL069119

25. V. Rodríguez-Méndez, V.M. Eguíluz, E. HernándezGarcía, J.J. Ramasco, Percolation-based precursors of transitions in extended systems. Sci. Rep. (2016). https://doi.org/10.1038/srep29552

26. J. Meng, J. Fan, Y. Ashkenazy, A. Bunde, S. Havlin, Forecasting the magnitude and onset of el niño based on climate network. New J. Phys. 20, 043036 (2018). https://doi.org/10.1088/1367-2630/aabb25

27. J. Ludescher et al., Improved el niño forecasting by cooperativity detection. Proc. Natl. Acad. Sci. 110, 1174211745 (2013)

28. A. Rheinwalt et al., Teleconnections in climate networks: A network-of-networks approach to investigate the influence of sea surface temperature variability on monsoon systems, in Machine Learning and Data Mining Approaches to Climate Science, ed. by V. Lakshmanan, E. Gilleland, A. McGovern, M. Tingley (Springer, Berlin, 2015), pp. 23-33

29. D. Zhou, A. Gozolchiani, Y. Ashkenazy, S. Havlin, Teleconnection paths via climate network direct link detection. Phys. Rev. Lett. 115, 268501 (2015)

30. N. Boers, B. Bookhagen, N. Marwan, J. Kurths, Spatiotemporal characteristics and synchronization of extreme rainfall in South America with focus on the andes mountain range. Clim. Dyn. 46, 601-617 (2016). https://doi.org/10.1007/s00382-015-2601-6

31. E. Ser-Giacomi, V. Rossi, C. López, E. HernándezGarcía, Flow networks: A characterization of geophysical fluid transport. Chaos: An interdisciplinary. J. Non- linear Sci. 25, 036404 (2015). https://doi.org/10.1063/ 1.4908231

32. R.V. Donner, E. Hernández-García, E. Ser-Giacomi, Introduction to focus issue: Complex network perspectives on flow systems. Chaos: An Interdisciplinary. J. Nonlinear Sci. 27, 035601 (2017). https://doi.org/10. 1063/1.4979129

33. M. Gelbrecht, N. Boers, J. Kurths, A complex network representation of wind flows. Chaos 27, 35808 (2017)

34. C. Vera et al., The South American low-level jet experiment. Bull. Am. Meteorol. Soc. 87, 63-77 (2006). https://doi.org/10.1175/BAMS-87-1-63

35. G.A.M. Silva, T. Ambrizzi, Inter-El Niño variability and its impact on the South American low-level jet east of the andes during austral summer-two case studies. Adv. Geosci. 6, 283-287 (2006). https://doi.org/10. 5194/adgeo-6-283-2006

36. W.D. Bonner, Climatology of the low level jet. Month. Weather Rev. 96, 833-850 (1968)

37. M.G. de Nascimento, D.L. Herdies, D.O. de Souza, The South American water balance: The influence of lowlevel jets. J. Clim. 29, 1429-1449 (2016)

38. P. Salio, M. Nicolini, A.C. Saulo, Chaco low-level jet events characterization during the Austral summer season. J. Geophys. Res. (2002). https://doi.org/10.1029/ 2001JD001315

39. M.M. Rienecker et al., Merra: Nasas modern-era retrospective analysis for research and applications. J. Clim. 24, 3624-3648 (2011). https://doi.org/10.1175/ JCLI-D-11-00015.1

40. E. Kalnay et al., The ncep/ncar 40-year reanalysis project. Bull. Am. Meteorol. Soc. 77, 437-471 (1996)

41. A.A. Tsonis, K.L. Swanson, P.J. Roebber, What do networks have to do with climate? Bull. Am. Meteorol. Soc. 87, 585-595 (2006). https://doi.org/10.1175/ BAMS-87-5-585

42. M. Newman, Networks: An Introduction (OUP Oxford, Oxford, 2010)

43. A. Rheinwalt, N. Marwan, J. Kurths, P. Werner, F.W. Gerstengarbe, Boundary effects in network measures of spatially embedded networks. Europhys. Lett. 100, $28002(2012)$

44. K. Wolter, M .S. Timlin, El niño/southern oscillation behaviour since 1871 as diagnosed in an extended multivariate enso index (mei.ext). Int. J. Climatol. 31, 10741087 (2011). https://doi.org/10.1002/joc.2336

45. G.A.M. Silva, T. Ambrizzi, J.A. Marengo, Observational evidences on the modulation of the south american low level jet east of the andes according the enso variability. Ann. Geophys. 27, 645-657 (2009)

46. R.D. Garreud, Cold air incursions over subtropical South America: Mean structure and dynamics. Month. Weather Rev. 128, 2544-2559 (2000)

47. N. Boers et al., Propagation of strong rainfall events from southeastern South America to the central andes. J. Clim. 28, 7641-7658 (2015). https://doi.org/10.1175/ JCLI-D-15-0137.1

48. N. Boers, B. Bookhagen, N. Marwan, J. Kurths, Spatiotemporal characteristics and synchronization of extreme rainfall in South America with focus on the andes mountain range. Clim. Dyn. 46, 601-617 (2016). https://doi.org/10.1007/s00382-015-2601-6

49. P. Salio, M. Nicolini, Seasonal characterization of the diurnal cycle of convection frequency over south amer- 
ica under different low-jet conditions. Proc. ICSHMO 8, 1157-1162 (2006)

50. R.N. Ferreira, T.M. Rickenbach, D.L. Herdies, L.M.V. Carvalho, Variability of South
American convective cloud systems and tropospheric circulation during January-maMch 1998 and 1999. Month. Weather Rev. 131, 961-973 (2003) 